Discussion Paper No. 18-023

\title{
Unemployment and Online Labor
}

Kathrin Borchert, Matthias Hirth, Michael Kummer, Ulrich Laitenberger,

Olga Slivko, and Steffen Viete

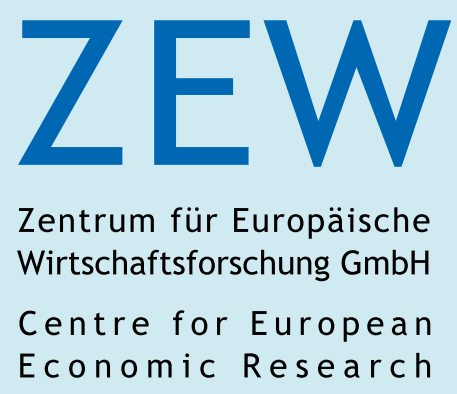


Discussion Paper No. 18-023

\title{
Unemployment and Online Labor
}

\author{
Kathrin Borchert, Matthias Hirth, \\ Michael Kummer, Ulrich Laitenberger, \\ Olga Slivko, and Steffen Viete
}

Download this ZEW Discussion Paper from our ftp server:

http://ftp.zew.de/pub/zew-docs/dp/dp18023.pdf

Die Discussion Papers dienen einer möglichst schnellen Verbreitung von neueren Forschungsarbeiten des ZEW. Die Beiträge liegen in alleiniger Verantwortung der Autoren und stellen nicht notwendigerweise die Meinung des ZEW dar.

Discussion Papers are intended to make results of ZEW research promptly available to other economists in order to encourage discussion and suggestions for revisions. The authors are solely responsible for the contents which do not necessarily represent the opinion of the ZEW. 


\title{
Unemployment and Online Labor*
}

\author{
Kathrin Borchert, Matthias Hirth† Michael Kummer; \\ Ulrich Laitenberger§, Olga Slivko, Steffen Vieteף
}

April 2018

\begin{abstract}
Online labor markets experienced a rapid growth in recent years. They allow for long-distance transactions and offer workers access to a potentially 'global' pool of labor demand. As such, they bear the potential to act as a substitute for shrinking local income opportunities. Using detailed U.S. data from a large online labor platform for microtasks, we study how local unemployment affects participation and work intensity online. We find that, at the extensive margin, an increase in commuting zone level unemployment is associated with more individuals joining the platform and becoming active in fulfilling tasks. At the intensive margin, our results show that with higher unemployment rates, online labor supply becomes more elastic. These results are driven by a decrease of the reservation wage during standard working hours. Finally, the effects are transient and do not translate to a permanent increase in platform participation by incumbent users. Our findings highlight that many workers consider online labor markets as a substitute to offline work for generating income, especially in periods of low local labor demand. However, the evidence also suggests that, despite their potential to attract workers, online markets for microtasks are currently not viable as a long run alternative for most workers.
\end{abstract}

Keywords: Unemployment; Crowdworking; Online platform.

JEL Classification Numbers: D29, D80, H41, J60, L17.

*We would like to thank Microworkers.com and especially Nhatvi Nguyen for providing us with the data for our analysis. Julia Baumann, Lukas Fortwengel and Tobias Werner provided outstanding research assistance. This work is supported by the State Government of Baden-Württemberg, Germany, through the research program 'Strengthening Efficiency and Competitiveness in the European Knowledge Economies' (SEEK) and the German Research Foundation (DFG) under Grants HO4770/2-2 and TR257/38-2. We thank participants of the 9th ICT Conference at Télécom ParisTech 2017, the 15th ICT Conference at the ZEW 2017, the Munich Doctoral Workshop on the Economics of Digitization 2017, Munich Summer Institute 2017, the Workshop on Flexible Work in the Digital Age 2017, ASSA 2018, and in particular Maya Bacache, Horst Entorf, Axel Gautier, Avi Goldfarb, Peter Rossi, Catherine Tucker, Le Wang and Christine Zulehner for helpful comments. The authors alone are responsible for the content.

${ }^{\dagger}$ University of Würzburg, Lehrstuhl für Informatik III, Am Hubland, 97074 Würzburg, Germany. E-mail: kathrin.borchert@informatik.uni-wuerzburg.de and matthias.hirth@informatik.uni-wuerzburg.de.

${ }^{\ddagger}$ Georgia Institute of Technology and ZEW (as below). E-mail: michael.kummer@econ.gatech.edu.

§Télécom ParisTech, 46 Rue Barrault, 75013 Paris, France, and ZEW (as below). E-mail: laitenberger@enst.fr.

『ZEW Centre for European Economic Research, L7, 168161 Mannheim, Germany. E-mail: slivko@zew.de and viete@zew.de. 


\section{Introduction}

Online labor markets (OLM) bear the promise of mitigating persistent frictions in offline labor markets caused by distance, transaction costs, skill mismatch, and limited geographic mobility of labor. By overcoming these barriers, OLM could reduce interregional inequality and contribute to economic growth, which is of interest to many policy makers.

The defining feature of OLM is that the product of labor is delivered entirely online (Horton, 2010), which allows for transactions over long distances between a potentially global pool of employers and employees. These markets are typically characterized by low entry barriers and in many cases offer jobs with low complexity, which do not require specialized skills. These features suggest that OLM could be attractive for underemployed or individuals who lost their job or local opportunities for employment in their local labor market.

In this paper, we study how local unemployment in the U.S. affects the adoption of and activity on a large online labor platform for microtasks (Microworkers.com). To study this question, we combine data from the microworking platform with unemployment statistics from the Bureau of Labor Statistics. To identify the effect of local unemployment on platform activity at the extensive and intensive margin, we exploit variation in unemployment at the commuting zone level in a set of fixed-effects panel regressions. Moreover, we use Bartik-style instrumental variables (IV) to instrument for local unemployment.

A main strength of our analysis is the fact that we use internal platform data from a large U.S.-based online labor market for microtasks which we can aggregate to the level of regional labor markets. Specifically, we use all data on platform activity by U.S. workers in the period from 2011 to 2015. Platforms for microtasks are highly suitable for the purpose of our analysis, because they constitute a major segment of OLM. Their main service is to allow for online 'mini contracts' between the employers and employees for performing relatively small and simple tasks which typically result from breaking down larger projects and business processes. Firms can submit orders that involve a large amount of similar 
'microtasks', such as image classification, to a crowd of interested workers. They also track the completion of tasks and submit payments, thus mediating the labor contract between employers and workers. The value created by these platforms appears to be high enough to ensure a steady growth of OLM over the last decade in terms of participants, transactions and variety of jobs mediated.

Our analysis of the relationship between unemployment and participation in the platform documents two main findings. First, at the extensive margin, an increase in commuting zone level unemployment is associated with more individuals joining the platform and becoming active in fulfilling tasks. The number of incumbent users engaging in tasks is unaffected though. Second, at the intensive margin, our results show that with higher unemployment rates, online labor supply becomes more elastic. We additionally find that

our results are driven by a decrease of the reservation wage during standard working hours.

Previous studies analyzed the individual motivations to participate in OLM (e.g. Horton and Chilton, 2010; Ross et al., 2010; Kaufmann et al., 2011; Ipeirotis, 2010) and the potential of online markets in overcoming geographic boundaries on an international scale (Agrawal et al., 2015; Gefen and Carmel, 2008). However, very few studies analyze the relationship between offline economic fluctuations and participation in OLM. Our study helps to fill this gap, providing insights into the potential of OLM to integrate local labor markets and act countercyclical on a subnational scale.

In the following, Section 2 connects the paper to related literature. Section 3 gives a short introduction to online labor platforms and microtasking and a description of the platform Microworkers.com. Section 4 discusses our empirical approach and Section 5 the data set. Section 6 and 7 report results, and Section 8 concludes.

\section{Related Literature}

Our paper contributes to several streams of the economic literature. A first major stream has sought to understand the drivers for the recent surge in OLM. This literature 
has mainly investigated the employees' motives, demographics and working conditions. We contribute by analyzing the role of unemployment for the supply of online labor. We furthermore contribute to the literature investigating the role of online intermediaries in integrating regional (labor) markets. In addition, our study is closely related to the literature interested in the labor supply to flexible and temporary work and the value of flexible work. Finally, we contribute to the literature of online time-use by highlighting to which extent variations in unemployment leads to online self-employment.

Our main contribution consists of analyzing to which extent activity in online microtasking is driven by local unemployment. We thus highlight the potential of OLM to counterbalance regional economic downturns and mitigate interregional economic disparities. In contrast to other online activities, crowdworking, i.e. the participation in OLM, offers participants explicit monetary rewards. This feature generates additional opportunities to earn income that complements offline labor markets. Although crowdworking markets for microtasks are known to yield a low level of earnings in comparison to the wage level in high-income countries, several studies suggest a high relevance of the direct compensation for participation in these markets (Kaufmann et al., 2011; Teodoro et al., 2014; Ipeirotis, 2010; Ross et al., 2010; Schnitzer et al., 2015). ${ }^{1}$ Horton and Chilton (2010) provide direct evidence on remunerations and earning targets in crowdworking platforms. ${ }^{2}$ Earnings on crowdworking platforms are found to be generally highly skewed (Agrawal et al., 2015; Hirth et al., 2011; Musthag and Ganesan, 2013), and average earnings largely depend on the nature and complexity of the tasks (Agrawal et al., 2015). ${ }^{3}$ Overall, existing

\footnotetext{
${ }^{1}$ Most of the evidence is available for the platform Amazon Mechanical Turk (MTurk), which is comparable to Microworkers.com in terms of nature of the tasks and payments. In a survey on participation motives conducted on MTurk by Kaufmann et al. (2011) direct compensation is the most important motive. Similarly, Teodoro et al. (2014) find the desire for monetary compensation to be among the main driver for engagement in an on-demand mobile crowdworking platform. However, Ipeirotis (2010) shows that most among U.S. participants on MTurk consider their work on the platform only as a secondary source of income. In a further survey conducted by Ross et al. (2010), around 10 percent of the US-based participants of MTurk indicate that they rely on the crowdworking income to make ends meet, while around one quarter of the participants indicate that the income is a way to pay for nice extras.

${ }^{2}$ Horton and Chilton (2010) estimate the reservation wage of a sample of crowdworkers on MTurk. They find that the median reservation wage is $\$ 1,38$ per hour, which also indicates that non-pecuniary motives for participation might also play a role for some users. In addition, the authors suggest that a non-trivial fraction of crowdworkers set earnings targets.

${ }^{3}$ Ross et al. (2010), for instance, discuss that on MTurk weekly earnings above $\$ 100$ are achieved only by 1 percent of the participants. Exploiting data from the online labor platform oDesk (now Upwork), Agrawal et al. (2015) show that average earnings do largely depend on the nature and complexity of
} 
studies suggest that remuneration is a strong motive for platform participation, even for online labor in the context of microtasks. ${ }^{4}$ On the other hand, findings on low reservation wages and average earnings in markets for microtasks indicate that OLM for microtasks, rarely (completely) substitute offline income. We address this debate by working with observational data and exploiting the variation in the local unemployment rate as shifter of the commuting zone's labor supply on the platform.

Whereas the relevance of compensation has been carefully documented, there is little evidence that relies on exogenous (to the platform) shifters of either wages or the labor supply. A notable exception is the study by Farrell and Greig (2016), who provide first suggestive evidence that individuals resort to OLM after negative income shocks. For their descriptive analysis, the authors used anonymized checking accounts data. Using data from a survey on MTurk and Crowdflower, Berg (2015) suggests that about one third of crowdworkers were unemployed prior to their engagement in online labor. A working paper by Cowgill and Horton (2018) focuses on participation in the Russian online labor market as a consequence of variations in the exchange rate and the ensuing changes in wage. Clearly, OLM could be particularly attractive for under- and unemployed individuals, because they offer jobs with low entry barriers, and often times jobs with low complexity, which require no specialized skills (Kuek et al., 2015). Most similar to our paper, Huang et al. (2017) use an identification strategy based on mass layoffs that differentially affect the online and other industries. They focus on freelancers and complex 'macrotasks', such as software development. In contrast to platforms for microtasks, the market analyzed involves considerably higher entry barriers, due to the need for specialized skills to perform the tasks. Moreover, more complex jobs and projects are typically available only once, whereas microtasks are made available in great number and thus create income opportunities for more individuals. Their results thus complement our

the tasks performed. Thus, average hourly earnings for software engineering tasks are $\$ 16$ and therefore twice the respective earnings for translation tasks. Similar differences in remunerations depending on task category have been documented for Microworkers.com by Hirth et al. (2011).

${ }^{4}$ Besides monetary incentives, the literature also highlights the importance of intrinsic motives for crowdworking (e.g. Brabham, 2010). Of particular relevance is the bigger autonomy with respect to the working time, the place, the content and the targeted earnings. Also, crowdworking provides opportunities to improve personal skills and experience. Finally, Ipeirotis (2010) highlights that crowdworking can also be perceived as personal entertainment. 
findings. What is completely missing however, is a systematic analysis of participation at the extensive and intensive margin, and the implied wage elasticities for online workers.

We contribute to the scarce empirical evidence on the potentials of online intermediaries to integrate labor markets. Regional mobility of the labor force is an important factor in equating interregional employment disparities and thus contributes to economic growth. However, persistent frictions in offline labor markets caused by distance and transaction costs are often important barriers to geographic mobility of labor (Artuc et al., 2015; Niebuhr et al., 2012). OLM have the potential to reduce such frictions and notable previous research on this critical and policy relevant question are the studies by Gefen and Carmel (2008) and Agrawal et al. (2015) with a focus on international cross-border transactions. Gefen and Carmel (2008) investigate transactions in an online programming marketplace for small IT projects. They find that employers tend to show preferences for domestic providers. However, the authors also document that American employers appear to be an exception to this finding, with higher preferences for offshore providers. Agrawal et al. (2015) show descriptively that, the online labor market oDesk is dominated by North-South exchange with employers being predominantly from highincome countries and contractors mainly form low income countries. Both studies point to the quality of OLM to foster cross-regional transactions on a global scale, which can be expected to be largely driven by international differences in factor prices. Taken together, these papers highlight how OLM contribute to the death of distance in international trade. We add to this stream by highlighting the integration of markets on a sub-national scale and studying its response to regional economic imbalances.

Our study is also related to the literature which is interested in quantifying the wage elasticity of labor supply in the context of flexible and temporary work. A considerable body of literature focuses on the labor supply decision of taxi drivers. This literature often finds small or negative labor supply elasticities consistent with earnings targets (Farber, 2015; Camerer et al., 1997). A famous experimental study by Fehr and Goette (2007) found higher wage elasticities of labor supply, but the increased supply of hours worked was flanked by reduced effort provision. Based on their own analysis of data from the 
online labor platform MTurk as well as an evaluation of 5 experiments run on the platform, Dube et al. (2018) document low labor supply elasticities of around 0.1, which they relate to monopsony power on the marketplace. We can contribute new insight to this massive stream of the literature, because our data set allows us to observe wage compensation and labor supply at an extremely high resolution (at the task level). Specifically, we also find low wage elasticities in general, but document considerably higher elasticities, when unemployment is high.

A related strand investigates the value of workplace flexibility. Mas and Pallais (2017) conduct a randomized experiment on the willingness to pay for schedule flexibility among call-center applicants. They find that the majority of applicants are not willing to pay for schedule flexibility, even though there is a considerable right tail of workers with high valuation. Chen et al. (2017) estimate the variation of the reservation wage of Uber drivers between hours. Simulating driver surplus, the authors find that Uber drivers benefit from the flexibility provided by on-demand online labor. We show how the supply of flexible online labor on OLM changes with unemployment. We thus contribute new insight on the role of local shocks to unemployment as another possibly important factor that might contribute to the transition to more flexible labor markets.

Finally, we contribute to the literature on online time usage by showing how the aggregate supply of labor on OLM changes over time of the day as unemployment increases. The literature suggests that young people (Wallsten, 2013) as well as poorer people (Goldfarb and Prince, 2008) spend more time online. At times of economic crisis both these groups of population are in danger of staying persistently unemployed and facing a subsequent decrease in their income. Our study adds to this literature by showing that individuals turn to OLM while spending time on their computers.

To summarize, it remains unclear whether or not the online labor market can serve as an alternative to offline labor markets. Specifically, more research is needed to explore the extent to which OLM interact and counterbalance macroeconomic fluctuations on a sub-national scale.

We aim at narrowing this gap by contributing the first comprehensive study that 
combines statistical U.S. data on commuting zone level unemployment with proprietary data from a microtasking platform. In addition, we provide a unified framework for relating both the number of participating users (extensive margin) and the amount of supplied labor (intensive margin) to the current rate of unemployment. This framework allows us to document how increased unemployment affects the labor supply elasticity. We thus inform both policy makers and stakeholders in online labor platforms about the potentials and shortcomings of OLM for microtasks to serve as a backup for workers in regions that experience negative shocks to labor demand.

\section{Microtasking Platforms}

\subsection{Online Labor Platforms and Microtasking}

The advent of OLM was marked by Amazon launching their platform MTurk in 2005. Ever since, the market for online labor has steadily grown. Aggregating information from the ten most important platforms, Frei (2009) estimated that by 2009 about $\$ 700$ million had been earned by individuals in OLM. In 2012, the World Bank estimated the global market size for microtasking in particular to be between $\$ 450$ and $\$ 900$ million annually, with an overall employment between 1.45 and 2.9 million workers (Rossotto et al., 2012). The Financial Times estimated the overall crowdworking market to be worth $\$ 1$ billion annually by 2012 (Agrawal et al., 2015). More recently, several studies have taken different approaches to assess the economic relevance of OLM for the U.S. Harris and Krueger (2015) indirectly try to estimated the number of individuals engaging in online labor based on search queries. Farrell and Greig (2017) identify online workers through transfers by major online labor platforms to their bank accounts. Katz and Krueger (2016) provide an estimate based on a representative online survey. Applying a broad definition of online mediated labor, including platforms for physical tasks provided locally, these studies uniformly find that between 0.4 and 0.5 percent of the U.S. labor force actively provided services over such platforms in 2015 and 2016.

Historically, online labor platforms started with the mediation of microtasks, i.e. 
small and repetitive tasks which can be performed quickly, such as writing small texts, recognizing pictures, providing transcriptions or verifying the accuracy of data. Several surveys are aimed at better understanding the demographic characteristics of users on online labor platforms (Ipeirotis, 2010; Ross et al., 2010; Martin et al., 2017). Martin et al. (2017) discuss that most demographic studies on MTurk find the majority of workers to be U.S. based (50\%-60\%). Based on their own survey conducted on the platforms MTurk, Crowdee and Microworkers.com, and in line with other studies on the topic, the authors show that most crowdworkers across platforms exhibit a high eduction level with a with a college or advanced degree and that online labor platforms tend to be dominated by male workers.

As the overall market for online labor has grown, platform heterogeneity has increased. This refers to both the nature of mediated labor and how the competing markets differ in critical aspects of their design such as payment models or competition. By now, the variety of tasks in OLM is much larger and ranges from very simple microtasks up to completing complex design or IT projects with substantial budgets and long durations. Platforms for microtasks differ from markets for complex tasks in various ways other than job complexity. The study by Agrawal et al. (2015) allows insights into how the platform oDesk mediates more complex jobs such as software development or customer services and sales and marketing jobs. For instance, rather than paying a fixed rate per microtask, oDesk also supports hourly wages. Moreover, employers can interview job applicants and negotiate the wages.

\subsection{Description of Microworkers.com}

Microworkers.com was launched in May, 2009. It is a 'classical' online platform for microtasks, with jobs ranging form writing reviews and articles to click and search tasks. ${ }^{5}$ In contrast to many other online labor platforms, users of Microworkers.com have only one login and can act as both, worker and employer. Payments are conducted via online micro-payment services, thus no bank account in a specific country is required. Tasks on

\footnotetext{
${ }^{5}$ For a detailed description of the platform see Hirth et al. (2011).
} 
Microworkers.com are organized in jobs and campaigns with one campaign consisting of multiple jobs to be performed. On Microworkers.com there are predefined job categories with different minimum payments depending on the complexity, time and effort required. The individual jobs are paid between $\$ 0.10$ and a few dollars. Types of tasks available on Microworkers.com range from very small and simple tasks, such as search engine optimization, to software testing, surveys and slightly more complex tasks, such as writing articles or audio transcripts. Hirth et al. (2011) document how earnings are highly dependent on the complexity of the respective task. Over time, the range of supported tasks has increased and especially more complex tasks have become available (Hirth, 2016).

To become active on the platform individuals have to register providing basic information, such as their name and email address. Once registered by a verified email address, individuals can view the marketplace and thus get information on the tasks that are available to them. In order to start working, individuals additionally have to verify their account by a phone number and a verification message. Employers can define eligible worker groups based on basic characteristics, such as country of origin or platform rating. Figure 1 shows a screenshot of the marketplace for a newly registered user. For each task the user is provided with information on the payment, the success rate of previously performed tasks in the campaign, the share of tasks in the campaign already done, the estimated time it takes to finish the task (in minutes, based on employer information) and the time the employer needs to rate the work output of the employee. Each tasks provides detailed instructions and requirements upon which the individual can accept the task and start working. After completing the tasks, the employer has the option to accept or reject the work output or demand a revision. In case of acceptance, the employee gets paid. Employees who feel they have been misrated can file a complaint, which is resolved by the platform. The reputation system rates employees according to their success rate, which is the relation of successful to non-successful tasks. To be able to continue performing tasks, employees have to keep their success rate above 75 percent.

By 2016, Microworkers.com had about 800,000 registered user, who submitted over 261,000 campaigns and had completed over 26 million tasks (Hirth, 2016). Hirth et al. 
Figure 1: Screenshot of the Microworkers.com Marketplace

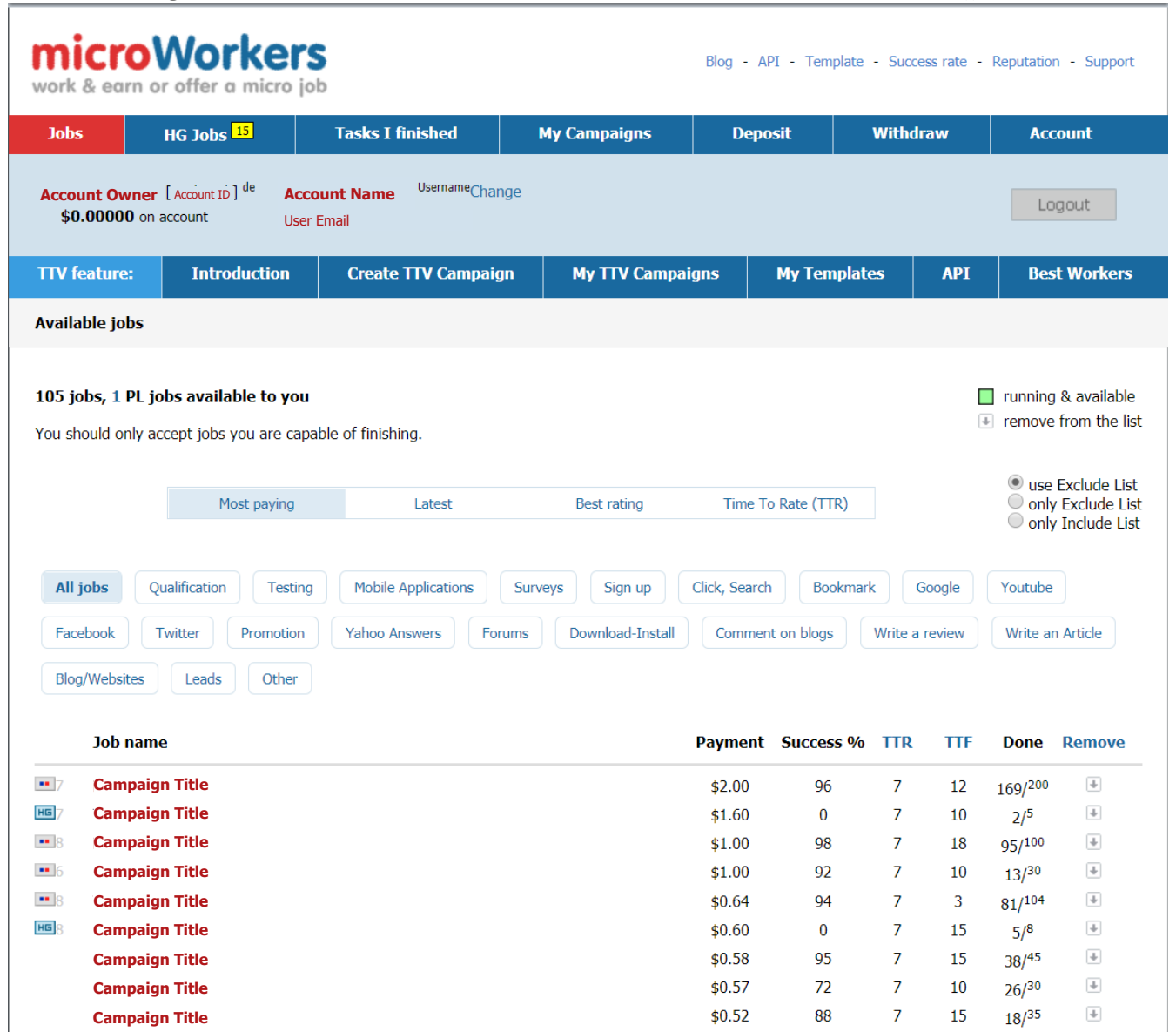

Note: Account details and campaign titles anonymized.

(2011) compare Microworkers.com to MTurk. Empirically, they find that the workers are less U.S.-centered on Microworkers.com than on MTurk. Thus, working hours can be different on average. However, U.S. citizens make up for one of the three biggest groups on Microworkers.com, and we solely focus on this subgroup of workers. Further differences relate to employers and hence the tasks demanded. Employers on Microworkers.com are less concentrated in the sense that 10 percent of employers account for 70 percent of the wage paid, compared to 90 percent of the wages paid on MTurk. Hirth et al. (2011) argue that this is due to MTurk being used more by mediators for other companies while on Microworkers.com employers are more often self-employed or use the platform for marketing purposes. Hence, creative tasks are slightly less present on Microworkers.com compared to MTurk. To sum up, Microworkers.com is conceptually a typical example of a microtasking platform as MTurk. The platform matches demand for tasks to be solved with supply of online workers, assures the fulfillment of tasks and facilitates the transfer 
of payments. The complexity of tasks is rather low and aimed to be done by a mass of users rather than a one-to-one relationship.

\section{Methodology}

\subsection{Model}

Our analysis focuses on U.S. citizens performing tasks on the platform between 2011 and 2015, and our data originate directly from the platform's records. Workers from the U.S. make up for the third largest country share of workers on the platform. In our empirical application, we are interested in the decision to work on the platform at the extensive as well as at intensive margin. Therefore, we first describe a simple discrete choice model of labor supply for the amount of work performed (intensive labor supply model). Subsequently, we describe the decision of workers to register and become active on the the platform.

Intensive labor supply model Wages on the platform are set by the task givers and microworkers are therefore wage-takers. We argue that any labor force member of the U.S. is a potential microworker. Any potential worker has a certain time endowment. It is upon the potential workers to make a choice to dedicate a time unit to fulfill a task on the platform. Each worker is willing to engage in doing some tasks on the platform in exchange for money, depending on the wage and the associated disutility of doing the task. The disutility of performing the task is inversely related to the reservation wage: the reservation wage is higher for less attractive or more demanding tasks that require more effort. (see also Chen et al., 2017). Both individual characteristics and the task type affect the individual's reservation wage. For instance, unemployed individuals could have a lower reservation wage due to their lower alternative income possibilities. Thus, they are more prone to spend time working on the platform. We assume that any participant of the labor force in a given commuting zone makes a decision how to make use of each time unit (measured by minutes) per quarter. 
To describe the decision of an individual to perform tasks in the online labor market, we make use of the discrete choice literature (Berry, 1994). We model the potential microworker $i$ 's conditional indirect utility from performing a task of type $j$ at each point in time in a logit framework as

$$
u_{i j}=X_{i j} \alpha+\beta w_{j}+\gamma w_{j} U R_{i, j}+\xi_{j}+\epsilon_{i j}
$$

where the variable $w_{j}$ denotes the wage per hour for task $j$ which is set by the employer submitting task $j . X_{i j}$ contains several observed task characteristics, commuting zone and time fixed effects. $\xi_{j}$ accounts for unobserved (by the econometrician) task characteristics. The vector $\alpha$ captures valuations by individuals for task characteristics, $\beta$ is the marginal utility of wage when the unemployment rate, $U R_{i, j}$, is at zero, $\gamma$ measures the perceived additional utility of wage interacted with the unemployment rate. $\epsilon_{i j}$ is as an i.i.d. extreme value distributed error term. The outside option captures other work opportunities online or offline as well as the option of not working at all. The outside option is normalized so that it has mean conditional utility of zero: $u_{i 0}=\epsilon_{i 0}$.

Applying the inversion steps suggested by Berry (1994) yields the following regression equation

$$
\ln \left(s_{j}\right)-\ln \left(s_{0}\right)=X_{i j} \alpha+\beta w_{j}+\gamma w_{j} U R_{j}+\xi_{j},
$$

which allows us to use aggregated data. Without taking into account the unemployment rate, we expect $\beta$ to have a positive sign, indicating that the remuneration contributes positively to the utility of performing the task. Additionally, we expect that unemployed have a higher utility when working on the platform as their outside option is less valuable once they do not have a job anymore. This should translate into $\gamma$ having a positive sign.

After estimating the model, we can calculate the own-wage elasticity of task supply by

$$
\frac{w_{j}}{s_{j}} \frac{\partial s_{j}}{\partial w_{j}}=\eta_{w}=\left(\beta+\gamma U R_{j}\right) w_{j}\left(1-s_{j}\right)
$$

As we specify in more detail below, we obtain the data aggregated by task type, 
commuting zone and quarter. Two additional layers - hour of the day and day of the week - are added later. We use this augmented data for robustness checks to show that unemployment affects platform activity most in the morning, when most people work.

Entry to the platform In addition to the intensive labor supply model, we also study the decision to work on the platform at the extensive margin. For this, we slightly adapt the model in Equation (2). Now, the choice set $J$ only consists of the outside option and joining the platform (the coefficient for task wage is omitted), such that

$$
u_{i, j}^{E n t r y}=X_{i, j} \alpha+\beta U R_{i, j}+\xi_{j}+\epsilon_{i, j}
$$

and we estimate

$$
\ln \left(s_{j}^{\text {Entry }}\right)-\ln \left(s_{0}^{\text {Entry }}\right)=X_{j} \alpha+\beta U R_{i}+\xi_{j}^{\text {Entry }}
$$

where $s_{e, j}$ is the share of individuals who register on the platform or perform at least one task in the quarter studied. We estimate Equation (5) for the number of newly registered and the number of active users, differentiated by newly active and incumbent users. The corresponding own-unemployment elasticity of online labor supply at the extensive margin is given by

$$
\frac{U R_{j}}{s_{j}} \frac{\partial s_{j}}{\partial U R_{j}}=\eta_{U R}=\beta U R_{j}\left(1-s_{j}\right)
$$

\subsection{Identification}

\section{Unobserved heterogeneity between commuting zones and shocks on the na-} tional level over time In order to mitigate a potential omitted-variable bias, we exploit the panel property of our data and include commuting zone fixed effects. We thus eliminate all variation in platform activity caused by time-invariant unobserved heterogeneity between local labor markets. Shocks at the national level and the potential ongoing adoption process on the platform is captured by the most conservative definition 
of time dummies as quarter fixed effects.

Endogeneity of wage As the online wage is an equilibrium outcome one could object that it is endogenous. However, online wages are set by the employers in the global (worldwide) market. As we use data on the commuting zone level, it is reasonable to assume that the effect of the local commuting zone wage level on the equilibrium online wage on the platform is negligible. Instead, as labor supply to the platform within one commuting zone is small compared to the total (worldwide) labor supply on the platform, we assume that individuals within a commuting zone face a perfectly inelastic labor demand.

Endogeneity of unemployment Unemployment might not only vary due to changes in local labor demand, but could equally well be due to labor supply shocks and thus be correlated e.g. with demographics (age-, skill structure). Trends in unemployment and participation in OLM could also be mutually driven by other commuting zone-specific characteristics which vary over time, such as digital infrastructure. When local labor market conditions get worse, young individuals might be driven out of the region. If younger individuals are also more likely to engage in online work, then our estimates would be downward biased. If economic hardship results in worse internet infrastructure, which is needed to work online, then our estimates would be upward biased. In contrast, endogeneity due to reverse causation is highly unlikely due to the still minor economic relevance of any single online labor platform to date.

In order to mitigate potential endogeneity of unemployment, we follow a standard approach in the literature on local labor market conditions and use Bartik, or "shift share' instruments. ${ }^{6}$ As an instrumental variable for local unemployment we construct a measure of plausibly exogenous labor demand shocks. For that, we interact predetermined cross-sectional differences in the industrial composition within a local labor market with

\footnotetext{
${ }^{6}$ This approach goes back to Bartik (1991) and has been used extensively in studies on local labor demand (e.g. Blanchard and Katz, 1992; Bound and Holzer, 2000; Autor and Duggan, 2003; Autor et al., 2013; Kroft and Notowidigdo, 2016; Adelino et al., 2017) or migration (e.g. Altonji and Card, 1991). In particular, Gould et al. (2002); Fougère et al. (2009) or Brown and De Cao (2017) use Bartik shocks to identify causal effects of local unemployment.
} 
national changes in industry employment (excluding own region employment). Formally, the local labor demand shock is constructed as

$$
\pi_{c t}=\sum_{k=1}^{K} \gamma_{c, k, t_{0}}\left(\frac{E_{-c, k, t}-E_{-c, k, t-1}}{E_{-c, k, t-1}}\right)
$$

where $\gamma_{c, k, t_{0}}$ is the employment share of industry $k$ in commuting zone $c$ and base period $t_{0}$ and $E_{-c, k, t}$ is the respective national employment in period $t$ excluding commuting zone $c$. We construct this Bartik shock at the 4-digit NAICS level according to the above equation. In order to construct pre-determined industry shares we use the year 2010 as base period. The concept behind this identification strategy is that when certain industries experience a nation-wide shock, some regions are affected more strongly due to their preexisting economic structure. Nation-wide industry growth excluding the focal commuting zone is plausibly exogenous due to the small size of individual commuting zones relative to the whole of the U.S. While the initial industry structure might be correlated with unobservable regional characteristics, we rely on predetermined, time invariant industry shares and control for commuting zone fixed effects in all our models.

\section{The Data}

\subsection{Data Set Creation}

Sources We want to assess the impact of a rise in unemployment in a local labor market on the participation on the online labor platform. We thus generate a data set combining information on platform activity with administrative data on economic activity in local labor markets. We use data on registrations and task completion by U.S. workers on Microworkers.com, which is based directly on the platform's internal data base. Although the platform was launched in 2009, we only use data from January, 2011 on to avoid that our results are confounded by early life-cycle features of the platform. We add data on the local labor force and unemployment, which stem form the Local Area Unemployment Statistics (LAUS) by the Bureau of Labor Statistics (BLS). Data on wages 
and employment by industry are taken from the Bureau of Labor Statistics' Quarterly Census of Employment and Wages (QCEW). We complement this data with information on local demographics from the Annual County Resident Population Estimates by the U.S. Census Bureau. ${ }^{7}$

Aggregation In order to have a meaningful delineation of local labor markets, we aggregate the data to commuting zones. These are defined by the U.S. Department of Agriculture in order to represent local labor markets (Tolbert and Sizer, 1996; Autor et al., 2013) and have become a widely used unit of observation in research on labor markets. They are constructed as clusters of counties with strong commuting ties within and weak commuting ties across commuting zones. Based on the regional mobility of workers, they are a more appealing definition of local labor markets than other alternatives, such as counties or metropolitan statistical areas. ${ }^{8}$ In the U.S. there are 709 commuting zones. We drop 52 commuting zones without any activity on the platform and thus arrive at a sample of 657 local labor markets. We use quarters as our primary observational time unit. We observe each commuting zone over 20 quarters from January 2011 until December 2015, leaving us with 13140 commuting zone-quarter observations.

Additional panel dimensions As outlined in Section 4.1 we create three main data sets with different panel dimensions for the three types of analysis we conduct. For our analysis at the extensive margin, where we model the decision of individuals within a commuting zone to enter the platform, we create a panel where the unit of observation is the commuting zone by quarter. We use this data to model the choice to register and become active on the platform according to Equation (5). For the analysis at the intensive margin, where we model the task supply by individuals within the commuting

\footnotetext{
${ }^{7}$ Local demographics data at the county level are only available at the yearly basis. Given that demographic characteristics have low variation over time, we linearly interpolate the yearly data in order to match them to our quarterly data.

${ }^{8}$ For the aggregation of county level data to commuting zones, we use the 2000 version of the crosswalk files provided by the U.S. Department of Agriculture. We manually updated the crosswalk file to match regional identifiers in our administrative data up to the year 2016 using publicly available information by the U.S. Census Bureau, the U.S. Centers for Disease Control and Prevention and by David Dorn at http://www.ddorn.net/data.htm.
} 
zone according to Equation (2), we additionally aggregate the platform data by task type. In particular, we distinguish between three types of tasks depending on how much effort is needed to finish the task: low, medium and high complexity. We assign low complexity to tasks that require few clicks and a short amount of time. These are, for example, providing an email address, signing up, image quality rating, or bookmark a page. To medium complexity we assign such tasks as writing a short comment to somebody's post or a short post on own timeline of Facebook, or write a short comment. These tasks do not typically require more than 5 minutes. Finally, highly complex tasks are those requiring longer than 5 minutes time for their accomplishment and a certain level of creativity, for example: write a post on a forum and provide a link, make a video or audio transcription or translation.

In Section 7.1, we conduct an analysis by the time of the day. We therefore construct a panel by quarter and commuting zone with the additional panel dimensions being the day of the week and the hour of the day.

\subsection{Descriptive Statistics}

Table 1 displays the descriptive statistics for the regressors and outcome variables used in the analysis. For reasons of confidentiality, all variables containing information on the platform are normalized with respect to their maximum value (over all commuting zones and time) in the sample (and are therefore defined between 0 and 1). "New registrants" is the number of new users in a specific commuting zone and quarter. Active users are defined as those who perform at least one task in the relevant quarter. In addition, we further distinguish between users who are newly active (for the first time) in the respective quarter and those who had already been active in previous quarters.

We furthermore measure the total number of working hours (Working hours), the number of tasks performed within a state (Tasks done) and the total payments earned by employees within a state (Paid reward). As the actual working hours are not observable, we measure total working hours by the time which the employer indicated the tasks would take when posting the campaign. Due to differences in the size of commuting 
Table 1: Descriptive Statistics

\begin{tabular}{lcccc}
\hline \hline & Mean & Std. Dev. & Min. & Max. \\
\hline New registrants & 0.02 & 0.06 & 0.00 & 1.00 \\
Active Users & 0.02 & 0.06 & 0.00 & 1.00 \\
Active Users (new) & 0.02 & 0.05 & 0.00 & 1.00 \\
Active Users (old) & 0.02 & 0.05 & 0.00 & 1.00 \\
Tasks & 0.00 & 0.02 & 0.00 & 1.00 \\
Working Hours & 0.01 & 0.02 & 0.00 & 1.00 \\
Wage sum & 0.01 & 0.02 & 0.00 & 1.00 \\
Population (Mio.) & 0.39 & 0.78 & 0.01 & 8.70 \\
Offline wage & 9.63 & 1.90 & 6.26 & 26.28 \\
Unemployed (Mio.) & 0.02 & 0.05 & 0.00 & 1.08 \\
Employed (Mio.) & 0.22 & 0.56 & 0.00 & 8.49 \\
Labor Force (Mio.) & 0.24 & 0.60 & 0.00 & 9.04 \\
Unemployment Rate & 0.07 & 0.03 & 0.01 & 0.29 \\
\% age 15-24 (i) & 0.24 & 0.03 & 0.15 & 0.45 \\
\% age 25-44 (i) & 0.41 & 0.03 & 0.28 & 0.54 \\
\% age 45-64 (i) & 0.35 & 0.04 & 0.23 & 0.51 \\
\% male (i) & 0.50 & 0.02 & 0.46 & 0.59 \\
\% white (i) & 0.84 & 0.14 & 0.11 & 0.99 \\
\hline Observations & 13140 & & & \\
\hline \hline
\end{tabular}

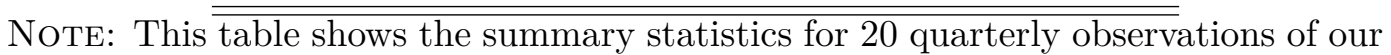
main variables of interest for 657 commuting zones. The variables are organized in two groups: (1) Aggregate participation and activity of U.S. residents on Microworkers.com. Active users performed at least one task in the respective quarter, and all indicators are normalized by the maximum value of each indicator respectively. (2) Demographic characteristics for the commuting zones in our data set. (i) Yearly data linearly interpolated to the quarterly level.

zones, the sample values for platform activity are highly skewed. Standard deviations for the measures of the number of users, registered and active users are higher than for the measures of volume.

There is a substantial number of commuting zones with zero activity. We deal with this in the following way. For the analysis of the extensive margin, we add one worker for all variables in order to be able to compute an odds-ratio. Therefore, we have a balanced panel for the number of newly registered users. For the active users, we only use commuting zones with a positive stock of registered users. For the analysis of the intensive margin, we use a sample of commuting zones where we could measure activity. Robustness analyses here show that the inclusion of zero activity commuting zones increases statistical power of instruments while leaving the results qualitatively unchanged.

The average commuting zone in our estimation sample has a population size of 0.39 
million, with a labor size of 0.24 million of which on average 0.02 million are unemployed. The average unemployment rate in our sample is around 7 percent. Regarding demographics, we report three age groups with the middle group being between 25 and 44 being on average the largest. The average share of males is at 50 percent, while on average 84 percent are white. Finally, the average quarterly wages per employee in the commuting zone are at 9.63 thousand U.S. Dollars.

\subsection{Activity on the Platform and Unemployment}

Figure 2: Aggregate Participation and Activity of U.S. Residents on Microworkers.com.

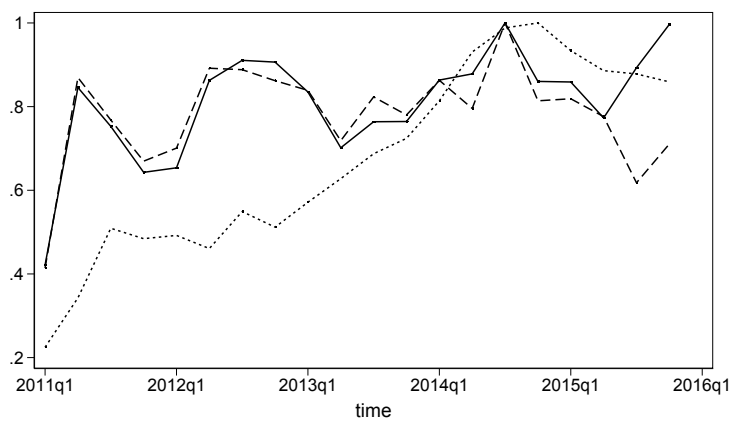

Newly reg. users $\quad$ - - - Active users (new) -....... Active users (old)

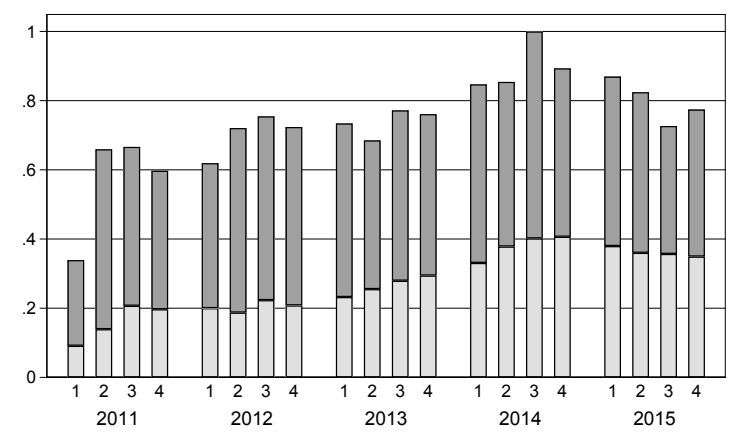

$\square$ \#AU old $\square$ \#AU new

NoTE: This figure displays the aggregate participation and activity of U.S. residents on Microworkers.com. Active users are defined as users that performed at least one task in the respective quarter. All indicators are normalized by the maximum value of each indicator respectively.

To better understand the extent of variation in the data across commuting zones or states, and over time, we report several figures on platform activity and unemployment. Figure 2 shows different measures for activities of U.S. users on the platform from the beginning of 2011 to the end of 2015. The number of newly registered users and the number of new active users follow a similar pattern. This suggests that most users who register perform their first tasks in the same month. The right panel of Figure 2 indicates that both the number of new and old active users were growing until 2014 and saw a small decrease in 2015. Figure 3 shows the distribution of registered user over commuting zones. The map plots quintiles of total registered user over our observation period. As expected, activity in the online labor market is concentrated at the east and the west coast of the U.S. 
In what follows, we show a visual analysis of the variation in unemployment and registration rates at the platform over time. Our main data is at the commuting zone level. However, for improved visualization and readability, we aggregated these variables at the state and monthly level.

Figure 3: Geographic Distribution of Registered User

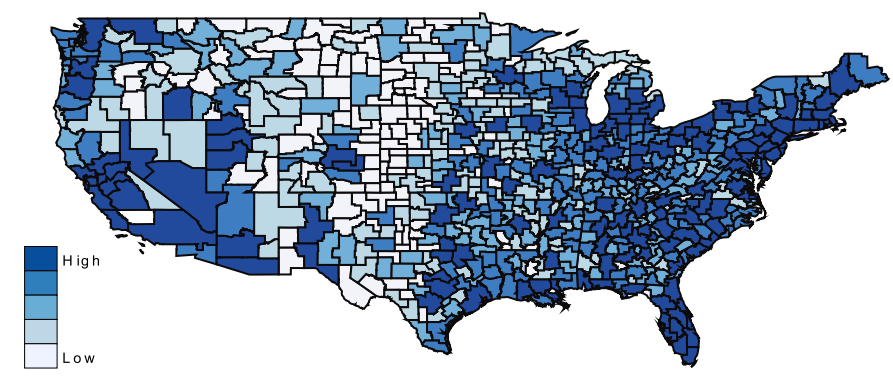

Note:The map plots quintiles of total registered user over the observation period. Dark regions belong to the highest quintile and light regions to the lowest.

Figure 4 shows the variation in the data at the state level. The left panel shows the unemployment rates and the right panel shows the number of users that registered on Microworkers.com. State-level unemployment rates were on an overall downward trend over the five year period, but we also observe a considerable variation across states over time, especially when comparing the 10th and the 90th percentiles to the median state. The right panel shows the number of newly registered users on Microworkers.com. To account for state size effects, new users are shown as a share of the state's labor force. The registration rate varies substantially across states and it shows a positive trend. Moreover, both measures, unemployment and registrations, exhibit a seasonal pattern. While the overall median trend of both series suggests a negative relationship, the plotted series do not account for differences in the baseline unemployment rates between states.

We further provide a better insight on the variation in the data by calculating the deviation of the state-level unemployment rate from the state-level average in the observation period and compare this to the registrations. In Figure 5, we plot the deviation of the unemployment rate from the state specific mean against the state-specific registration rate. The figure shows that in months with high relative unemployment the number of registrations tends to be higher as well. The correlation coefficient between both variables 
Figure 4: State-level Unemployment and Registrations on Microworkers.com.

Unemployment Rate

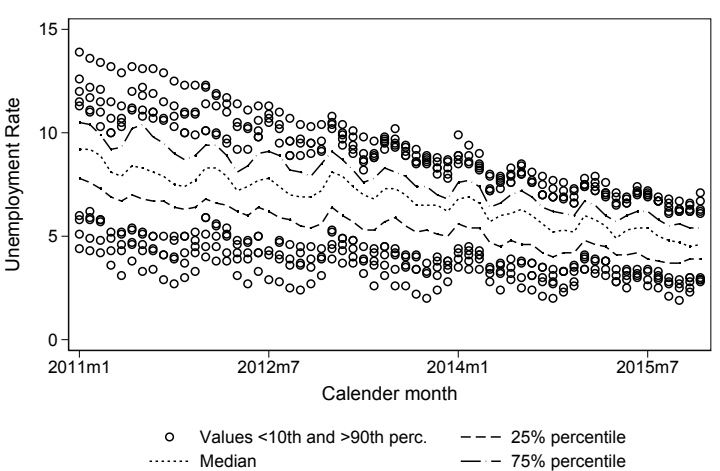

New Registrations on Microworkers.com

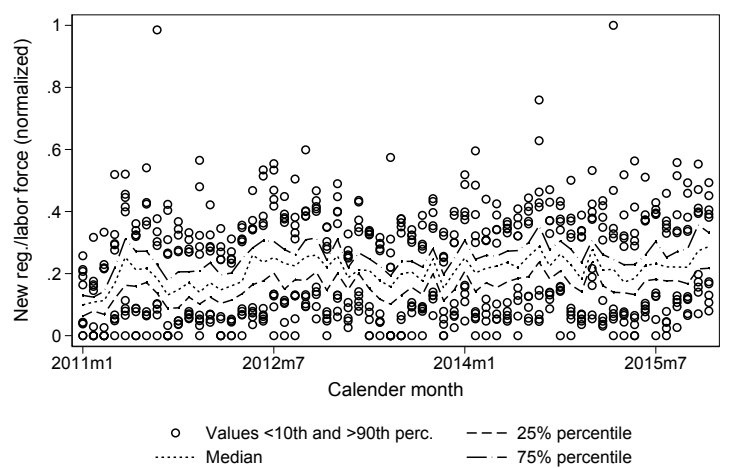

Note: This figure displays the percentiles of the unemployment rates and the registration rate on Microworkers.com. It also indicates outliers above the highest and below the lowest 10th percentile. Registration rates are calculated as the number of registrations divided by the labor force. They are normalized by the maximum value of all states over time.

is 0.55 . The positive association in Figure 5 provides a first descriptive evidence for the relevance of local unemployment for platform participation.

Figure 5: Unemployment Rates and Corresponding Registrations on Microworkers.com.

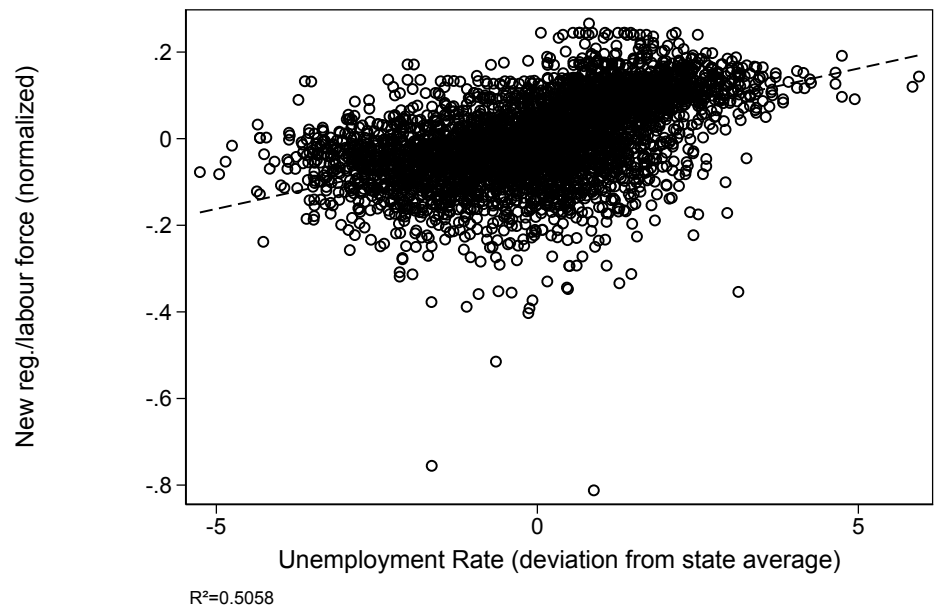

Note: This figure plots deviations form the state-specific average unemployment rate on the horizontal axis against the (normalized) state-specific registration rates on the vertical axis. 


\section{Main Results}

We present three sets of findings. First, we analyze the effect of unemployment on the participation of new users or the extensive margin (Subsection 6.1). We use simple OLS fixed effects and Bartik IV methods. In Subsection 6.2 we analyze the intensive margin, that is the hours that users worked on the platform. In Section 7 we explore the robustness and heterogeneities in the effects across demographic groups and hours of the day.

\subsection{Extensive Margin Labor Supply}

To estimate how unemployment affects entry of workers to the platform we estimate Equation 5 from Section 4. That is, we analyze the effect of unemployment on the participation on the platform, using our data on all commuting zones. To quantify participation, we focus on user registrations and user activity in commuting zone $i$ and period $t$. Table 2 shows the regression results. All regressions are OLS fixed effects regressions and the dependent variable measures the odds-ratio of newly registered users (Col. (1)), all active users on the platform (Col. (2)). In Columns 3 and 4 we distinguish between active users who registered to the platform and performed tasks within the quarter (Col. (3)) and active users who already performed tasks in an earlier quarters (Col. (4)).

We find a strong positive relationship between registrations and unemployment and a weakly significant positive relationship between the number of active users and unemployment (cf. Col. 2), which is driven by new active users rather than existing users (Col. 3 and 4). In line with expectations, the relationship between the local level of offline wages are negatively associated with registrations and the number of active users. These findings suggest that with an increase in unemployment, more users register and perform at least one task. In our OLS fixed effects regressions, we find rather moderate elasticities. These suggest that a one percent increase in the unemployment rate, is associated with a 0.09 percent increase in number of newly registered user and the number of active user. Similarly, a one percent increase in the unemployment rate is associated with a 0.11 
Table 2: Results on the Extensive Margin

\begin{tabular}{lcccc}
\hline \hline & Reg. Users & Active Users & Active Users (New) & Active Users (Old) \\
& $(1)$ & $(2)$ & $(3)$ & $(4)$ \\
\hline Unemployment Rate & $1.314^{* * *}$ & $1.671^{*}$ & $2.091^{* *}$ & 0.221 \\
& $(0.508)$ & $(0.896)$ & $(0.888)$ & $(0.920)$ \\
Offline wage & $-0.054^{* * *}$ & -0.022 & $-0.023^{*}$ & 0.009 \\
& $(0.010)$ & $(0.014)$ & $(0.013)$ & $(0.014)$ \\
\% age 15-24 (i) & $-6.563^{* * *}$ & 0.274 & 2.026 & -3.172 \\
& $(1.558)$ & $(3.132)$ & $(2.864)$ & $(3.777)$ \\
$\%$ age 45-64 (i) & -0.161 & 4.467 & 1.651 & $10.809^{* *}$ \\
& $(1.726)$ & $(3.990)$ & $(3.515)$ & $(4.405)$ \\
$\%$ male (i) & -4.215 & -13.393 & -7.737 & -18.540 \\
& $(4.170)$ & $(10.561)$ & $(9.803)$ & $(11.615)$ \\
$\%$ white (i) & $4.336^{*}$ & $-13.004^{* *}$ & $-11.981^{* *}$ & $-23.946^{* * *}$ \\
& $(2.339)$ & $(5.146)$ & $(4.643)$ & $(5.908)$ \\
Constant & $-10.055^{* * *}$ & $15.383^{*}$ & $12.136^{*}$ & $25.360^{* * *}$ \\
& $(3.270)$ & $(7.922)$ & $(7.288)$ & $(8.936)$ \\
Time FE & Yes & Yes & Yes & Yes \\
\hline$R^{2}$ Overall & 0.01 & 0.00 & 0.00 & 0.01 \\
$R^{2}$ Within & 0.08 & 0.58 & 0.63 & 0.61 \\
Observations & 13140 & 10950 & 10950 & 10950 \\
UR elasticity & 0.09 & 0.09 & 0.11 & 0.01 \\
Offl. Wage elast. & -0.52 & -0.16 & -0.17 & 0.07 \\
\hline
\end{tabular}

NOTE: The table analyzes the relationship of unemployment and user participation on Microworkers.com. The dependent variable measures the odds-ratio of newly registered users (Col. (1)), all active users on the platform (Col. (2)). Columns 3 and 4 separately consider newly registered users who were active in the quarter (Col. (3)) and active users who already performed tasks in past quarters (Col. (4)). All regressions are OLS fixed effects regressions. Standard errors in parentheses are clustered by commuting zone and are robust to heteroscedasticity and autocorrelation. ${ }^{*} \mathrm{p}<0.1,{ }^{* *} \mathrm{p}<0.05,{ }^{* * *} \mathrm{p}<0.01$.

percent increase in users who perform tasks during their first quarter on the platform. As for the labor supply elasticity with respect to the offline wage level, we find that a one percent increase in offline wages relates to a decrease in the number of newly registered users by 0.52 percent and a decrease in the number of newly active users by 0.17 percent.

Identification of the Effect of Unemployment with Bartik IVs In Table 3 we revisit the analysis of the extensive margin (Equation 5 from Section 4), but we account for the endogeneity of the unemployment rate and use Bartik shocks to instrument unemployment, as outlined in Section 4.2. When we use this instrumentation strategy, all signs of the previous regressions are confirmed. Unemployment continues to have a statistically significant effect on registrations and the number of newly active users, and the 
Table 3: Results on the Extensive Margin, Instrumented with Bartik IVs

\begin{tabular}{lcccc}
\hline \hline & $(1)$ & $(2)$ & $(3)$ & $(4)$ \\
& Reg. Users & Active Users & Active Users (New) & Active Users (Old) \\
\hline Unemployment Rate & $11.385^{* *}$ & 7.888 & $12.643^{* *}$ & 8.440 \\
& $(3.993)$ & $(6.475)$ & $(6.199)$ & $(6.019)$ \\
Offline wage & $-0.048^{* *}$ & -0.016 & -0.013 & 0.016 \\
& $(0.011)$ & $(0.015)$ & $(0.014)$ & $(0.015)$ \\
\% age 15-24 (i) & $-7.150^{* *}$ & 0.356 & 2.166 & -3.064 \\
& $(1.820)$ & $(3.166)$ & $(2.923)$ & $(3.860)$ \\
\% age 45-64 (i) & 1.933 & 5.448 & 3.317 & $12.107^{* *}$ \\
& $(2.103)$ & $(4.084)$ & $(3.667)$ & $(4.552)$ \\
\% male (i) & $-13.599^{* *}$ & -23.004 & -24.047 & $-31.245^{* *}$ \\
& $(6.515)$ & $(15.336)$ & $(14.716)$ & $(15.488)$ \\
\% white (i) & $9.264^{* *}$ & $-10.303^{*}$ & -7.397 & $-20.375^{* *}$ \\
& $(3.381)$ & $(6.191)$ & $(5.797)$ & $(6.671)$ \\
Time FE & Yes & Yes & Yes & Yes \\
\hline Observations & 13140 & 10945 & 10945 & 10945 \\
Kleibergen-Paap Stat & 27.02 & 18.05 & 18.05 & 18.05 \\
UR elasticity & 0.80 & 0.40 & 0.67 & 0.46 \\
Offl. Wage elast. & -0.46 & -0.12 & -0.10 & 0.13 \\
\hline \hline
\end{tabular}

NoTE: This table replicates Table 2 but instruments local unemployment with Bartik instruments. The dependent variable measures the odds-ratio of newly registered users (Col. (1)), all active users on the platform (Col. (2)). Columns 3 and 4 separately consider newly registered users who were active in the quarter (Col. (3)) and active users who already performed tasks in past quarters (Col. (4)). All regressions are two stage least squares fixed effects regressions. First stage results are provided in Table A.1. Standard errors in parentheses are clustered by commuting zone and are robust to heteroscedasticity and autocorrelation. ${ }^{*} \mathrm{p}<0.1,{ }^{* *} \mathrm{p}<0.05$, $* * * \mathrm{p}<0.01$.

offline wage level is negatively associated with user registrations. The effect of unemployment on the number of total active users however, is not statistically significant any more at conventional levels. We note that using Bartik IV to account for endogeneity of local unemployment considerably increases the magnitude of the labor supply elasticity with respect to unemployment compared to the OLS estimates. However, the elasticities remain below one and within reasonable range. According to our IV estimates, a one percent increase in local unemployment leads to a 0.8 percent increase in the number of newly registered user and a 0.67 percent increase of newly active users in the OLM.

\subsection{Intensive Margin Labor Supply}

We now turn to the analysis of the intensive margin of labor supply. This implies studying how local unemployment affects the hours that users devote to working on the 
platform. For this, we estimate the model described in Equation 2 of Section 4 . We use a data set with one additional panel dimension, the task categories according to their complexity. The dependent variable is the odds-ratio of hours worked. We exclude commuting zones without active users, given that only active users can vary their hours worked on the platform.

In Column (1) of Table 4, we estimate the model with OLS fixed effects for the commuting zones, including the platform wage and dummies for the task categories (with simple tasks being the omitted category). All coefficients are in line with expectations. Wage affects the utility of doing a task positively, while disutility increases with the complexity of tasks. Applying Equation (3) from Section 4 to back out the wage elasticity of labor supply, we find a moderate average wage elasticity of 0.15. In Column (2) we interact the platform wage with the local unemployment rate. The interaction yields a positive coefficient, implying a higher utility of wage in areas with higher unemployment. Users from areas with high unemployment increase are thus willing to work more for the same wage, which is in line with the fact that their opportunity cost is lower when being unemployed. In Column (3) we instrument local unemployment with Bartik shocks. We observe that the instrument increases the interaction of the platform wage and the unemployment rate, but that the Kleibergen-Paap statistic is low. ${ }^{9}$ In order to account for the low first-stage F-statistic, we also report the p-value for the Anderson-Rubin test. ${ }^{10}$ As the respective p-value is very low, this increases our trust in the instrument.

In line with expectations, labor supply in online labor becomes more elastic after an increase in the local unemployment rate. We observe a higher valuation of wages (higher labor supply elasticity) when the unemployment rate is high. Moreover, while the average wage elasticity is negative when we instrument unemployment, it is positive in the areas with higher unemployment rates. Specifically, we computed the elasticities for

\footnotetext{
${ }^{9}$ This is due to the omission of commuting zones without activity. We redid the IV estimation including commuting zones with zero tasks performed. The respective observations are created by adding one minute of performed work to all observations to avoid zeros. We observe that coefficients when allowing for commuting zones without activity lie between specification (2) and (3), and the instrument yields a considerably higher first stage F-statistic.

${ }^{10}$ For applied examples using Anderson-Rubin tests for weak-instrument robust inference see Nunn and Qian (2014) or Asatryan et al. (2017).
} 
Table 4: Results on the Intensive Margin Labor Supply

\begin{tabular}{lccc}
\hline \hline & $(1)$ & $(2)$ & $(3)$ \\
& OLS & OLS & IV \\
\hline Platform wage & $0.016^{* * *}$ & -0.013 & $-0.245^{* *}$ \\
& $(0.004)$ & $(0.014)$ & $(0.104)$ \\
Medium task complexity & $-1.416^{* * *}$ & $-1.403^{* * *}$ & $-1.301^{* * *}$ \\
& $(0.038)$ & $(0.039)$ & $(0.058)$ \\
High task complexity & $-2.406^{* * *}$ & $-2.399^{* * *}$ & $-2.344^{* * *}$ \\
& $(0.069)$ & $(0.069)$ & $(0.073)$ \\
Unemployment X Wage & & $0.320^{* *}$ & $2.873^{* *}$ \\
& & $(0.140)$ & $(1.147)$ \\
Time FE & Yes & Yes & Yes \\
\hline Observations & 16416 & 16416 & 16416 \\
Adjusted $R^{2}$ & 0.32 & 0.32 & 0.25 \\
Model & fe & fe & iv \\
Kleibergen-Paap Stat & & & 9.94 \\
Anderson-Rubin p-val. & & & 0.00 \\
Wage Elasticity & 0.16 & 0.11 & -0.26 \\
at UR $<5 \%$ & & 0.00 & -0.99 \\
at 5\% $<=$ UR $<10 \%$ & & 0.10 & -0.31 \\
at 10\% $<=$ UR $<20 \%$ & & 0.32 & 1.14 \\
at UR $>=20 \%$ & & 0.62 & 4.39 \\
\hline \hline
\end{tabular}

Note: The dependent variable measures the odds-ratio of working hours on Microworkers.com. Columns (1) and (2) are OLS fixed effects regressions and Column (3) is estimated by two stage least squares fixed effects. Respective first stage results are provided in Table A.2. Standard errors in parentheses are clustered by commuting zone and are robust to heteroscedasticity and autocorrelation. ${ }^{*} \mathrm{p}<0.1,{ }^{* *} \mathrm{p}<0.05,{ }^{* * *} \mathrm{p}<0.01$.

several intervals and found that it is positive (and increasing) for commuting zones with unemployment rates higher than 6.5 percent.

\section{Exploring Effect Heterogeneity}

\subsection{Effect Heterogeneity Across Hours of the Day}

While our analysis, so far, indicates that platform activity increases with a rise in local unemployment, a remaining question is whether online labor acts primarily as a complement or a substitute to traditional offline labor in times of regional economic downturns. In this section, we further investigate the role of online labor and study systematically how wage elasticities change with increased unemployment across the hours of the day. This analysis helps us to further pin down the mechanism that drives the 
findings above, because it allows us to test whether our results are indeed driven by unemployed workers in the local labor market, rather than individuals who generally struggle under adverse local economic conditions. If the effects we measure are driven by unemployed workers, we expect to see larger effects of regional unemployment on online labor supply during regular working hours. To study at which times of the day unemployment has an effect on labor supply in the online labor market, we augment our data set with two additional panel dimensions: the weekday and hour of the day. ${ }^{11}$ The dependent variable is as in Subsection 6.2 the odds-ratio of working hours. In order to increase readability, we use three hour intervals, but results do not change qualitatively for hourly intervals.

The results for the labor supply model accounting for hours of the day are shown in Table 5. We separately show our results for all days of the week (Col. 1-2) and then contrast regular weekdays (Col. 3) with weekends (Col. 4). The estimates indicate that workers have a lower valuation for the wage for working during nights after midnight and on weekends (Col. 1). In Column 2 we add interactions of the unemployment rate with wage and hour of the day indicators to the model, in order to investigate during which parts of the day the effect of unemployment is strongest. The results show that users have an increased valuation for wage between 6-12 and 18-0 when the unemployment rate increases. Importantly, the effects are strongest in size during the morning. When contrasting weekdays (Col. 3) and weekends (Col. 4) we see that the effect is positive in the morning hours in both cases. However, the increase in the early morning is driven by the activity on weekdays, whereas the wage valuation increase on the weekends starts later in the morning and goes over noon. Overall, we find the strongest effect of unemployment on labor supply on the platform during morning hours, which correspond with regular working hours. Thus, rather than acting as a mere complement to offline income, when unemployment rises individuals substitute online labor for tasks they would typically perform during regular working hours.

We graphically illustrate this finding in Figure 6. Panel B contrasts the share of reg-

\footnotetext{
${ }^{11}$ The hour of the day refers to local time, i.e. we correct server time for the respective time zone.
} 
Table 5: Labor Supply Model by Hour of the Day

\begin{tabular}{|c|c|c|c|c|}
\hline & $\begin{array}{l}(1) \\
\text { All }\end{array}$ & $\begin{array}{l}(2) \\
\text { All }\end{array}$ & $\begin{array}{c}(3) \\
\text { During Week }\end{array}$ & $\begin{array}{c}(4) \\
\text { Weekend }\end{array}$ \\
\hline Medium task complexity & $\begin{array}{c}-1.605^{* * *} \\
(0.099)\end{array}$ & $\begin{array}{c}-1.229^{* * *} \\
(0.109)\end{array}$ & $\begin{array}{c}-1.302^{* * *} \\
(0.114)\end{array}$ & $\begin{array}{c}-1.045^{* * *} \\
(0.105)\end{array}$ \\
\hline High task complexity & $\begin{array}{c}-0.765^{* * *} \\
(0.095)\end{array}$ & $\begin{array}{c}-0.722^{* * *} \\
(0.095)\end{array}$ & $\begin{array}{c}-0.768^{* * *} \\
(0.096)\end{array}$ & $\begin{array}{c}-0.605^{* * *} \\
(0.095)\end{array}$ \\
\hline Wage & $\begin{array}{c}0.075^{* * *} \\
(0.009)\end{array}$ & $\begin{array}{l}-0.032 \\
(0.022)\end{array}$ & $\begin{array}{c}-0.037 \\
(0.024)\end{array}$ & $\begin{array}{c}-0.039^{* *} \\
(0.020)\end{array}$ \\
\hline Wage X Hours 3-6 & $\begin{array}{c}-0.016^{* * *} \\
(0.002)\end{array}$ & $\begin{array}{l}-0.001 \\
(0.007)\end{array}$ & $\begin{array}{c}-0.006 \\
(0.008)\end{array}$ & $\begin{array}{l}0.017^{*} \\
(0.009)\end{array}$ \\
\hline Wage X Hours 6-9 & $\begin{array}{c}-0.016^{* * *} \\
(0.004)\end{array}$ & $\begin{array}{c}-0.052^{* * *} \\
(0.011)\end{array}$ & $\begin{array}{c}-0.055^{* * *} \\
(0.012)\end{array}$ & $\begin{array}{c}-0.042^{* * *} \\
(0.012)\end{array}$ \\
\hline Wage X Hours 9-12 & $\begin{array}{c}0.011^{* * *} \\
(0.004)\end{array}$ & $\begin{array}{c}-0.024^{* *} \\
(0.012)\end{array}$ & $\begin{array}{c}-0.020 \\
(0.012)\end{array}$ & $\begin{array}{c}-0.038^{* * *} \\
(0.014)\end{array}$ \\
\hline Wage X Hours 12-15 & $\begin{array}{c}0.015^{* * *} \\
(0.002)\end{array}$ & $\begin{array}{c}0.002 \\
(0.009)\end{array}$ & $\begin{array}{c}0.007 \\
(0.009)\end{array}$ & $\begin{array}{l}-0.014 \\
(0.011)\end{array}$ \\
\hline Wage X Hours 15-18 & $\begin{array}{c}0.024^{* * *} \\
(0.002)\end{array}$ & $\begin{array}{c}0.027^{* * *} \\
(0.007)\end{array}$ & $\begin{array}{c}0.033^{* * *} \\
(0.007)\end{array}$ & $\begin{array}{c}0.008 \\
(0.010)\end{array}$ \\
\hline Wage X Hours 18-21 & $\begin{array}{c}0.022^{* * *} \\
(0.002)\end{array}$ & $\begin{array}{c}0.007 \\
(0.007)\end{array}$ & $\begin{array}{c}0.005 \\
(0.007)\end{array}$ & $\begin{array}{c}0.014 \\
(0.009)\end{array}$ \\
\hline Wage X Hours 21-24 & $\begin{array}{c}0.015^{\text {*** }} \\
(0.002)\end{array}$ & $\begin{array}{l}-0.009 \\
(0.006)\end{array}$ & $\begin{array}{l}-0.012^{*} \\
(0.007)\end{array}$ & $\begin{array}{c}0.002 \\
(0.008)\end{array}$ \\
\hline Wage X Weekend & $\begin{array}{c}-0.011^{* * *} \\
(0.001)\end{array}$ & $\begin{array}{c}-0.025^{* * *} \\
(0.003)\end{array}$ & & \\
\hline Wage X UR & & $\begin{array}{c}0.840^{* * *} \\
(0.185)\end{array}$ & $\begin{array}{c}0.902^{\text {*** }} \\
(0.202)\end{array}$ & $\begin{array}{c}0.822^{* * *} \\
(0.173)\end{array}$ \\
\hline Wage X UR X Hours 3-6 & & $\begin{array}{c}-0.209^{* *} \\
(0.091)\end{array}$ & $\begin{array}{l}-0.141 \\
(0.105)\end{array}$ & $\begin{array}{c}-0.420^{* * *} \\
(0.120)\end{array}$ \\
\hline Wage X UR X Hours 6-9 & & $\begin{array}{c}0.453^{* * *} \\
(0.141)\end{array}$ & $\begin{array}{c}0.513^{* * *} \\
(0.155)\end{array}$ & $\begin{array}{l}0.284^{*} \\
(0.150)\end{array}$ \\
\hline Wage X UR X Hours 9-12 & & $\begin{array}{c}0.420^{* * *} \\
(0.130)\end{array}$ & $\begin{array}{c}0.392^{\text {*** }} \\
(0.138)\end{array}$ & $\begin{array}{c}0.518^{* * *} \\
(0.158)\end{array}$ \\
\hline Wage X UR X Hours 12-15 & & $\begin{array}{c}0.146 \\
(0.101)\end{array}$ & $\begin{array}{c}0.119 \\
(0.109)\end{array}$ & $\begin{array}{l}0.265^{* *} \\
(0.129)\end{array}$ \\
\hline Wage X UR X Hours 15-18 & & $\begin{array}{l}-0.045 \\
(0.082)\end{array}$ & $\begin{array}{l}-0.079 \\
(0.088)\end{array}$ & $\begin{array}{c}0.086 \\
(0.111)\end{array}$ \\
\hline Wage X UR X Hours 18-21 & & $\begin{array}{l}0.187^{* *} \\
(0.081)\end{array}$ & $\begin{array}{l}0.227^{* *} \\
(0.090)\end{array}$ & $\begin{array}{c}0.067 \\
(0.113)\end{array}$ \\
\hline Wage X UR X Hours 21-24 & & $\begin{array}{c}0.300^{* * *} \\
(0.075)\end{array}$ & $\begin{array}{c}0.354^{* * *} \\
(0.085)\end{array}$ & $\begin{array}{c}0.136 \\
(0.102)\end{array}$ \\
\hline Wage X UR X Weekend & & $\begin{array}{c}0.175^{\text {*** }} \\
(0.034)\end{array}$ & & \\
\hline Year Quarter ind. & Yes & Yes & Yes & Yes \\
\hline$R^{2}$ Overall & 0.15 & 0.16 & 0.17 & 0.15 \\
\hline$R^{2}$ Within & 0.18 & 0.18 & 0.19 & 0.18 \\
\hline Observations & 486814 & 486814 & 358794 & 128020 \\
\hline
\end{tabular}

Note: $\overline{\text { The table shows regressions of unemployment on the activity in the }}$ online labor market by the hour of the day. The dependent variable is the odds-ratio for working hours. Col. 1 shows the distribution of activity across the day, and in Columns 2-4 we introduce interactions of wage and the daily hours with unemployment. We separately show our results for all days of the week (Col. 1-2), and then separately for regular weekdays (Col. 3) and weekends (Col. 4). Standard errors in parentheses are clustered by commuting zone and robust to heteroscedasticity and autocorrelation. ${ }^{*} \mathrm{p}<0.1,{ }^{* *} \mathrm{p}<0.05,{ }^{* * *} \mathrm{p}<0.01$. 
Figure 6: Effect of Unemployment on Labor Supply by Hour of the Day
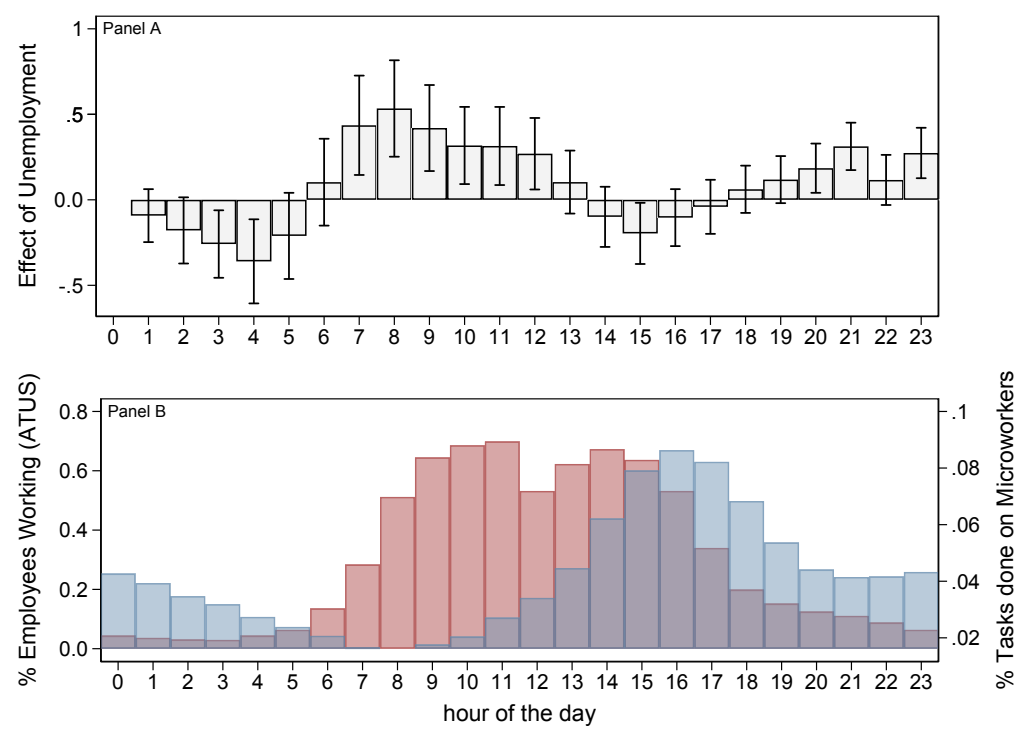

Note: Panel A: Effect of (unemployment $*$ wage) on the odds-ratio for working hours (relative to 0:00 omitted category). Panel B: Share of employees working according to American Time Use Survey (ATUS) (red) and distribution of tasks performed on Microworkers.com (blue). Over half the population is working by 8 AM (ATUS). Most activity on Microworkers.com after noon to midnight.

ular (offline) employees' working times according to American Time Use Survey (ATUS) with the temporal distribution of the tasks performed on Microworkers.com. While more than 60 percent of the regular employees work by 9 am in the ATUS data, the activity on Microworkers.com peaks in the afternoon and continues until after midnight. Both distributions illustrate that the workers on Microworker.com have a different behavior than the average working population, and they work most during afternoon and less during the early morning. This indicates that reservation wages may be different across the day.

Panel A visualizes the respective point estimates for the interaction term between platform wage and the local unemployment rate by the hour of the day. ${ }^{12}$ The graph again shows that we find the overall strongest positive effect of unemployment from 7 am to 9 am and positive and statistically significant effects until $1 \mathrm{pm}$. Comparing these positive effects with the respective ATUS data from Panel B shows that the positive effects of unemployment on platform activity mainly arise during regular working hours in the morning.

\footnotetext{
${ }^{12}$ The effects are derived from a regression analogous to the one in Table 5 but effects are estimated
} 
Figure 7: Labor Supply Elasticities by Hour of the Day

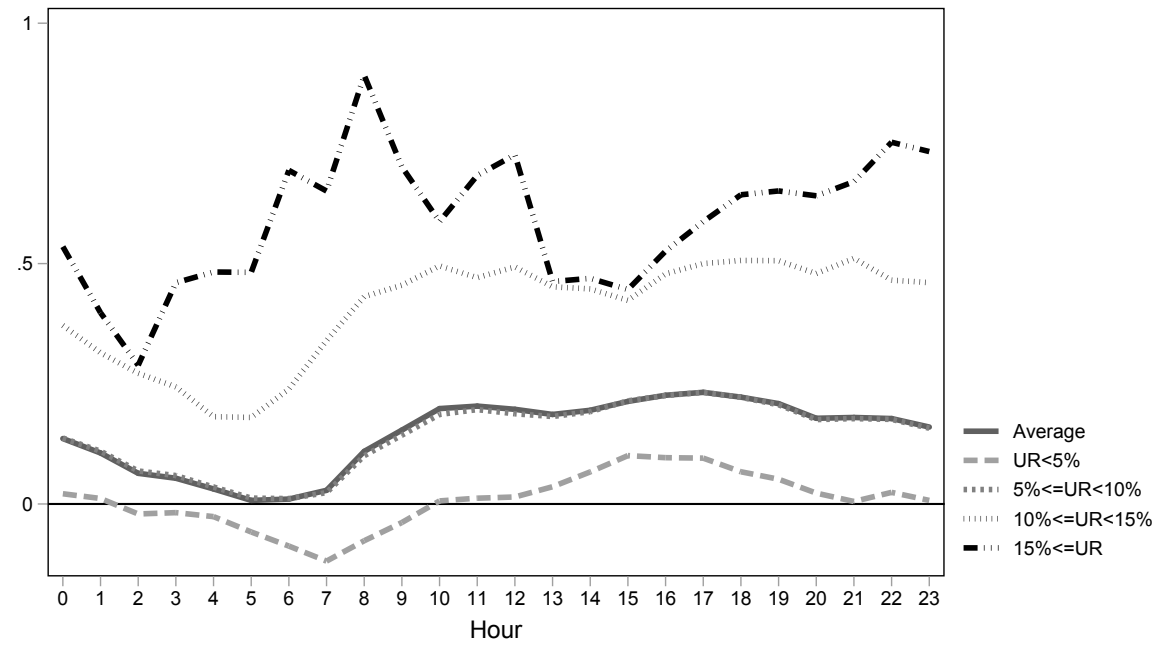

Note: The graph shows predicted wage elasticities of labor supply over the hours of the day for different levels of the unemployment rate. Calculations are based on the estimation results provided in Table A.3 in the appendix.

Finally, Figure 7 visualizes the profile of the respective average labor supply elasticities for different levels of unemployment and by the hour of the day. ${ }^{13}$ The predicted values show that there is considerable variation in labor supply elasticities across the day. For low local unemployment rates below 5 percent we predict negative labor supply elasticities from 2 am until 10 am. For average unemployment rates the elasticities are strictly positive and we find the highest elasticities in the afternoon. In line with the findings in Table 5, the graph shows that higher unemployment rates lead to a stronger relative increase in the wage elasticity during regular working hours in the morning.

\subsection{Effect Heterogeneity Along Demographics}

In this subsection we address the question how the effects of unemployment on platform participation vary by demographics. As there is no data available to measure unemployment by demographic groups directly at the necessary observational level, we resort to regressions in which we interact the local unemployment rate with demographics of the total local population.

for each individual hour. The full regression results can be found in Table A.3 in the appendix.

${ }^{13}$ The elasticities are derived from the same regression by individual hours as the one used for Figure

6. Unemployment rates are grouped in intervals. Detailed results can be found in Table A.3 in the 
Table 6: Results for Registrations - Interactions with Demographic Variables

\begin{tabular}{|c|c|c|c|c|}
\hline & $\begin{array}{l}\text { All } \\
(1)\end{array}$ & $\begin{array}{l}\text { Age } \\
(2)\end{array}$ & $\begin{array}{c}\text { Gender } \\
(3)\end{array}$ & $\begin{array}{c}\text { Race } \\
(4)\end{array}$ \\
\hline UR & $\begin{array}{c}1.314^{* * *} \\
(0.508)\end{array}$ & $\begin{array}{l}-0.092 \\
(5.579)\end{array}$ & $\begin{array}{c}-55.289^{* * *} \\
(12.457)\end{array}$ & $\begin{array}{c}-7.726^{* * *} \\
(1.879)\end{array}$ \\
\hline Offline wage & $\begin{array}{c}-0.054^{* * *} \\
(0.010)\end{array}$ & $\begin{array}{c}-0.055^{* * *} \\
(0.010)\end{array}$ & $\begin{array}{c}-0.049^{* * *} \\
(0.010)\end{array}$ & $\begin{array}{c}-0.053^{* * *} \\
(0.010)\end{array}$ \\
\hline$\%$ age $15-24(\mathrm{i})$ & $\begin{array}{c}-6.563^{* * *} \\
(1.558)\end{array}$ & $\begin{array}{l}-2.854 \\
(1.844)\end{array}$ & $\begin{array}{c}-6.417^{* * *} \\
(1.506)\end{array}$ & $\begin{array}{c}-5.187^{* * *} \\
(1.536)\end{array}$ \\
\hline$\%$ age $45-64(\mathrm{i})$ & $\begin{array}{l}-0.161 \\
(1.726)\end{array}$ & $\begin{array}{l}-1.304 \\
(1.835)\end{array}$ & $\begin{array}{c}-1.405 \\
(1.686)\end{array}$ & $\begin{array}{c}0.809 \\
(1.697)\end{array}$ \\
\hline$\%$ male (i) & $\begin{array}{l}-4.215 \\
(4.170)\end{array}$ & $\begin{array}{l}-4.412 \\
(4.086)\end{array}$ & $\begin{array}{c}-11.788^{* * *} \\
(4.181)\end{array}$ & $\begin{array}{l}-1.435 \\
(4.042)\end{array}$ \\
\hline$\%$ white (i) & $\begin{array}{l}4.336^{*} \\
(2.339)\end{array}$ & $\begin{array}{l}4.677^{* *} \\
(2.336)\end{array}$ & $\begin{array}{c}3.579 \\
(2.270)\end{array}$ & $\begin{array}{c}3.758 \\
(2.333)\end{array}$ \\
\hline $\mathrm{UR} \times \%$ age $15-24(\mathrm{i})$ & & $\begin{array}{c}-33.429^{* * *} \\
(12.383)\end{array}$ & & \\
\hline $\mathrm{UR} \times \%$ age $45-64(\mathrm{i})$ & & $\begin{array}{c}24.221^{* *} \\
(9.845)\end{array}$ & & \\
\hline $\mathrm{UR} \times \%$ male $(\mathrm{i})$ & & & $\begin{array}{c}113.160^{* * *} \\
(24.978)\end{array}$ & \\
\hline $\mathrm{UR} \times \%$ white $(\mathrm{i})$ & & & & $\begin{array}{c}10.675^{* * *} \\
(2.177)\end{array}$ \\
\hline Constant & $\begin{array}{c}-10.055^{* * *} \\
(3.270)\end{array}$ & $\begin{array}{c}-10.648^{* * *} \\
(3.193)\end{array}$ & $\begin{array}{l}-5.264 \\
(3.244)\end{array}$ & $\begin{array}{c}-11.620^{* * *} \\
(3.193)\end{array}$ \\
\hline Year Quarter ind. & Yes & Yes & Yes & Yes \\
\hline$R^{2}$ Overall & 0.01 & 0.01 & 0.01 & 0.01 \\
\hline$R^{2}$ Within & 0.08 & 0.09 & 0.09 & 0.09 \\
\hline Observations & 13140 & 13140 & 13140 & 13140 \\
\hline
\end{tabular}

NoTE: This table shows the results of regressing the number of registered users on the local unemployment rate and local demographics. Col. 1 shows the effect on demographics on overall platform registrations. Col. 2-4 show interactions between the commuting zone unemployment rate and the share of the demographic subgroup of interest. Col. 2 focuses on age, Col. 3 on gender and Col. 4 on race. OLS Fixed Effects Regressions. Standard errors in parentheses are clustered by commuting zone and robust to heteroscedasticity and autocorrelation. * $\mathrm{p}<0.1$, ** $\mathrm{p}<0.05$, *** $\mathrm{p}$ $<0.01$. 
Table 6 shows the results of regressing the number of user registrations on the local unemployment rate and local demographics. The estimation results in Column 2 show that unemployment interacted with the share of individuals in the age bracket of 45-64 years of age is positively related to new registrations on the platform, while the interaction with the share individuals between 15 and 24 years of age is negative and significant. Column 3 and 4 highlight that the relationship of local unemployment with registrations is higher in regions with higher shares of males and of white individuals in the population. Our results thus do not support the notion that OLM are particularly attractive for young unemployed individuals, but, instead, suggest that unemployment drives platform participation in regions with a higher share of white, male, and older population.

\section{Conclusion}

Online labor markets experienced considerable growth, because they offer a completely new way in which employer-employee matches are made. In contrast to traditional offline markets, which are historically highly localized, online labor markets allow for transactions over long distances and provide individuals on both sides of the market with the access to a wider, potentially global pool of participants. This feature of the emerging digital labor platforms highlights their potential to stimulate the integration of labor markets.

In this paper, we study the impact of local unemployment in the U.S. on the adoption of and activity on a large online labor platform for microtasks (Microworkers.com). We use internal data on platform activity by U.S. workers in the period from 2011 to 2015, and combine them with data on regional unemployment from the Bureau of Labor Statistics. Specifically, we study the effect of regional unemployment on platform activity at the extensive and intensive margin, by exploiting variation in unemployment at the commuting zone level. For identification, we apply fixed-effects panel regressions and Bartik style instrumental variables (IV) to instrument for regional unemployment. We find that higher commuting zone level unemployment is associated with more individuals joining

appendix. 
the platform and becoming active in fulfilling tasks (extensive margin). The number of incumbent users engaging in tasks is unaffected though. At the intensive margin, online labor supply becomes more elastic with higher unemployment rates. These results are driven by a decrease of the reservation wage during standard working hours.

This paper thus provides evidence that individuals turn to online labor markets in times of local economic hardship. It underlines pecuniary motives of platform participation and the potential of online platforms to integrate labor markets. The finding that the online labor platform saw more registrations in times of higher unemployment indicates that unemployed people are in principle willing to engage in online activities to achieve income.

Our findings have two implications. First, from a managerial perspective, platform operators should be well aware of unemployed people as potential clients of their platform and take this into account when developing their business model. Second, policy makers should think about possibilities to ease access to online labor markets and foster their use. However, our findings also suggest that online labor markets, at least for microtasks, cannot substitute offline work, at least not in our period of observation. There might be many reasons for this: First, online working in its current form might not yet be attractive enough. This could be related, for instance, to low wages or the kind of tasks currently offered. Second, it might well be that the amount of tasks offered is too rigid in the short run to account for an inflow of workers, thus leading to a non-availability or at least shortage of attractive tasks. Third, effects could be heterogeneous on circumstances. 


\section{References}

Adelino, Manuel, Song Ma, and David Robinson, "Firm Age, Investment Opportunities, and Job Creation," The Journal of Finance, 2017, 72 (3), 999-1038.

Agrawal, Ajay, John Joseph Horton, Nicola Lacetera, and Elizabeth Lyons, "Digitization and the Contract Labor Market: A Research Agenda," Economic Analysis of the Digital Economy, 2015, pp. 219-250.

Altonji, Joseph Gerard and David Card, "The Effects of Immigration on the Labor Market Outcomes of Less-Skilled Natives," in "Immigration, Trade, and the Labor Market," University of Chicago Press, 1991, pp. 201-234.

Artuc, Erhan, Daniel Lederman, and Guido Porto, "A Mapping of Labor Mobility Costs in the Developing World," Journal of International Economics, 2015, 95 (1), $28-41$.

Asatryan, Zareh, Benjamin Bittschi, and Philipp Doerrenberg, "Remittances and Public Finances: Evidence from Oil-Price Shocks," Journal of Public Economics, 2017, 155, 122-137.

Autor, David H. and Mark G. Duggan, "The Rise in the Disability Rolls and the Decline in Unemployment," The Quarterly Journal of Economics, 2003, 118 (1), 157206.

_, David Dorn, and Gordon H. Hanson, "The China Syndrome: Local Labor Market Effects of Import Competition in the United States," American Economic Review, 2013, $103(6), 2121-68$.

Bartik, Timothy J., Who Benefits from State and Local Economic Development Policies?, Kalamazoo, Mich: WE Upjohn Institute for Employment Research, 1991.

Berg, Janine, "Income Security in the On-demand Economy: Findings and Policy Lessons from a Survey of Crowdworkers," Comparative Labor Law \& Policy Journal, $2015,37,543-570$. 
Berry, Steven Titus, "Estimating Discrete-choice Models of Product Differentiation," The RAND Journal of Economics, 1994, pp. 242-262.

Blanchard, Olivier and Lawrence Francis Katz, "Regional Evolutions," Brooking Papers on Economic Activity, 1992, 23 (1), 1-75.

Bound, John and Harry Joseph Holzer, "Demand Shifts, Population Adjustments, and Labor Market Outcomes During the 1980s," Journal of Labor Economics, 2000, 18 (1), 20-54.

Brabham, Daren C., "Moving the Crowd at Threadless: Motivations for Participation in a Crowdsourcing Application," Information, Communication ES Society, 2010, 13 (8), $1122-1145$.

Brown, Dan and Elisabetta De Cao, "The Impact of Unemployment on Child Maltreatment in the United States," University of Oxford Department of Economics Discussion Paper Series, 2017, $83 \%$.

Camerer, Colin, Linda Babcock, George Loewenstein, and Richard Thaler, "Labor Supply of New York City Cabdrivers: One Day at a Time," The Quarterly Journal of Economics, 1997, 112 (2), 407-441.

Chen, Melvin Keith, Judith A. Chevalier, Peter E. Rossi, and Emily Oehlsen, "The Value of Flexible Work: Evidence from Uber Drivers," NBER Working Paper Series, 2017, No. 23296.

Cowgill, Bo and John Joseph Horton, "From Russia with Labor: The Effects of the Ruble Collapse in an Online Labor Market," Working Paper, 2018.

Dube, Arindrajit, Jeff Jacobs, Suresh Naidu, and Siddharth Suri, "Monopsony in Online Labor Markets," NBER Working Paper Series, 2018, No. 24416.

Farber, Henry Stuart, "Why you Can't Find a Taxi in the Rain and Other Labor Supply Lessons from Cab Drivers," The Quarterly Journal of Economics, 2015, 130 (4), 1975-2026. 
Farrell, Diana and Fiona Greig, "Paychecks, Paydays, and the Online Platform Economy: Big data on Income Volatility," JP Morgan Chase Institute, 2016.

_ and _, "The Online Platform Economy: Has Growth Peaked?," JP Morgan Chase Institute, 2017.

Fehr, Ernst and Lorenz Goette, "Do workers work more if wages are high? Evidence from a randomized field experiment," American Economic Review, 2007, 97 (1), 298317.

Fougère, Denis, Francis Kramarz, and Julien Pouget, "Youth Unemployment and Crime in France," Journal of the European Economic Association, 2009, 7 (5), 909-938.

Frei, Brent, "Paid Crowdsourcing: Current state \& Progress Toward Mainstream Business Use," Smartsheet White Paper, 2009.

Gefen, David and Erran Carmel, "Is the World Really flat? A Look at Offshoring at an Online Programming Marketplace,” MIS Quarterly, 2008, 32 (2), 367-384.

Goldfarb, Avi and Jeff Prince, "Internet Adoption and Usage Patterns are Different: Implications for the Digital Divide," Information Economics and Policy, 2008, 20 (1), $2-15$.

Gould, Eric D., Bruce A. Weinberg, and David Brendan Mustard, "Crime Rates and Local Labor Market Opportunities in the United States: 1979-1997," Review of Economics and Statistics, 2002, 84 (1), 45-61.

Harris, Seth D. and Alan B. Krueger, "A Proposal for Modernizing Labor Laws for Twenty-First-Century Work: The "Independent Worker"," The Hamilton Project Discussion Paper, 2015, 2015-10.

Hirth, Matthias, "Modeling Crowdsourcing Platforms - A Use-Case Driven Approach." Dissertation, Julius-Maximilians-Universität Würzburg 2016. 
_, Tobias Hoßfeld, and Phuoc Tran-Gia, "Anatomy of a Crowdsourcing Platform Using the Example of Microworkers.com," in "2011 Fifth International Conference on Innovative Mobile and Internet Services in Ubiquitous Computing" 2011, pp. 322-329.

Horton, John Joseph, "Online Labor Markets," in "International Workshop on Internet and Network Economics" Springer 2010, pp. 515-522.

_ and Lydia B. Chilton, "The Labor Economics of paid Crowdsourcing," in "Proceedings of the 11th ACM Conference on Electronic Commerce" ACM 2010, pp. 209-218.

Huang, Ni, Gordon Burtch, Yili Hong, and Paul A. Pavlou, "Unemployment and Worker Participation in the Gig Economy: Evidence from an Online Labor Platform," Working Paper, 2017.

Ipeirotis, Panagiotis G., "Demographics of Mechanical Turk," NYU Working Paper, 2010, CEDER-10-01.

Katz, Lawrence Francis and Alan Bennett Krueger, "The Rise and Nature of Alternative Work Arrangements in the United States, 1995-2015," NBER Working Paper Series, 2016, No. w2266\%.

Kaufmann, Nicolas, Thimo Schulze, and Daniel Veit, "More than Fun and Money. Worker Motivation in Crowdsourcing - A Study on Mechanical Turk.," in "Americas Conference on Information Systems," Vol. 11 2011, pp. 1-11.

Kroft, Kory and Matthew J. Notowidigdo, "Should Unemployment Insurance vary with the Unemployment Rate? Theory and Evidence," The Review of Economic Studies, 2016, 83 (3), 1092-1124.

Kuek, Siou Chew, Cecilia Paradi-Guilford, Toks Fayomi, Saori Imaizumi, Panos Ipeirotis, Patricia Pina, and Manpreet Singh, The Global Opportunity in Online Outsourcing, Washington: The World Bank, 2015.

Martin, David, Sheelagh Carpendale, Neha Gupta, Tobias Hoßfeld, Babak Naderi, Judith Redi, Ernestasia Siahaan, and Ina Wechsung, "Understand- 
ing the Crowd: Ethical and Practical Matters in the Academic Use of Crowdsourcing," in "Evaluation in the Crowd. Crowdsourcing and Human-Centered Experiments," Springer, 2017, pp. 27-69.

Mas, Alexandre and Amanda Pallais, "Valuing Alternative Work Arrangements," American Economic Review, 2017, 107 (12), 3722-59.

Musthag, Mohamed and Deepak Ganesan, "Labor Dynamics in a Mobile MicroTask Market," in "Proceedings of the SIGCHI Conference on Human Factors in Computing Systems" ACM 2013, pp. 641-650.

Niebuhr, Annekatrin, Nadia Granato, Anette Haas, and Silke Hamann, "Does Labour Mobility Reduce Disparities Between Regional Labour Markets in Germany?," Regional Studies, 2012, 46 (7), 841-858.

Nunn, Nathan and Nancy Qian, "US Food Aid and Civil Conflict," American Economic Review, 2014, 104 (6), 1630-66.

Ross, Joel, Lilly Irani, Michael Silberman, Andrew Zaldivar, and Bill Tomlinson, "Who are the Crowdworkers? Shifting Demographics in Mechanical Turk," in "CHI'10 extended abstracts on Human factors in computing systems" ACM 2010, pp. $2863-2872$.

Rossotto, Carlo Maria, Siou Chew Kuek, and Cecilia Paradi-Guilford, "New Frontiers and Opportunities in Work - ICT is Dramatically Reshaping the Global Job Market," The World Bank ICT Policy Notes, 2012, 03.

Schnitzer, Steffen, Christoph Rensing, Sebastian Schmidt, Kathrin Borchert, Matthias Hirth, and Phuoc Tran-Gia, "Demands on Task Recommendation in Crowdsourcing Platforms-The Worker's Perspective," in "ACM RecSys 2015 CrowdRec Workshop" Vienna 2015.

Teodoro, Rannie, Pinar Ozturk, Mor Naaman, Winter Mason, and Janne Lindqvist, "The Motivations and Experiences of the on-demand Mobile Workforce," 
in "Proceedings of the 17th ACM Conference on Computer Supported Cooperative Work \& Social Computing" ACM 2014, pp. 236-247.

Tolbert, Charles M. and Molly Sizer, "U.S. Commuting Zones and Labor Market Areas a 1990 Update," ERS Staff Paper, 1996, 9614.

Wallsten, Scott, "What are we not Doing when we're Online," NBER Working Paper Series, 2013, No. w19549. 


\section{Appendix}

\begin{tabular}{ccc} 
Table A.1: First Stage Regression - Extensive Mar \\
\hline \hline & Reg. Users & Active Users \\
& $(1)$ & $(2)$ \\
\hline Offline wage & $-0.001^{*}$ & $-0.001^{* *}$ \\
& $(0.000)$ & $(0.000)$ \\
\% age 15-24 (i) & 0.068 & -0.006 \\
& $(0.067)$ & $(0.071)$ \\
\% age 45-64 (i) & $-0.200^{* * *}$ & -0.155 \\
& $(0.075)$ & $(0.094)$ \\
\% male (i) & $0.932^{* * *}$ & $1.549^{* * *}$ \\
& $(0.221)$ & $(0.240)$ \\
\% white (i) & $-0.482^{* * *}$ & $-0.418^{* * *}$ \\
& $(0.110)$ & $(0.112)$ \\
Bartik shock & $-0.059^{* * *}$ & $-0.052^{* * *}$ \\
& $(0.011)$ & $(0.012)$ \\
Year Quarter ind. & Yes & Yes \\
\hline Observations & 13140 & 10945
\end{tabular}

Note: The table shows the first stage for the two stage least squares estimation results shown in Table 3 . The dependent variable is the local unemployment rate. Col. (1) provides the first stage for the analysis of registered users. Col. (2) provides the first stage for the analysis of active users in total, as well as newly active and old active users. Standard errors in parentheses are clustered by commuting zone and robust to heteroscedasticity and autocorrelation. ${ }^{*} \mathrm{p}<0.1,{ }^{* *} \mathrm{p}<0.05,{ }^{* * *} \mathrm{p}<0.01$. 
Table A.2: First Stage Regression - Intensive Margin

\begin{tabular}{lc}
\hline \hline & $(1)$ \\
\hline Medium task complexity & $-0.036^{* * *}$ \\
& $(0.002)$ \\
High task complexity & $-0.018^{* * *}$ \\
& $(0.003)$ \\
Platform wage & $0.089^{* * *}$ \\
& $(0.002)$ \\
Platf. wage X Bartik shock & $-0.051^{* * *}$ \\
& $(0.016)$ \\
Year Quarter ind. & Yes \\
\hline Observations & 16416
\end{tabular}

Note: The table shows the first stage for the two stage least squares estimation results shown in Table 4 . The dependent variable is the platform wage interacted with the local unemployment rate. Standard errors in parentheses are clustered by commuting zone and robust to heteroscedasticity and autocorrelation. ${ }^{*} \mathrm{p}<0.1,{ }^{* *} \mathrm{p}<0.05,{ }^{* * *} \mathrm{p}<0.01$. 
Table A.3: Labor Supply Model by Individual Hour of the Day

\begin{tabular}{|c|c|c|c|c|}
\hline & $\begin{array}{l}\text { (1) } \\
\text { All }\end{array}$ & $\begin{array}{l}(2) \\
\text { All }\end{array}$ & $\begin{array}{c}(3) \\
\text { During Week }\end{array}$ & $\begin{array}{c}(4) \\
\text { Weekend }\end{array}$ \\
\hline Platform wage & $\begin{array}{l}-0.043^{*} \\
(0.022)\end{array}$ & $\begin{array}{l}-0.032 \\
(0.022)\end{array}$ & $\begin{array}{l}-0.033 \\
(0.024)\end{array}$ & $\begin{array}{c}-0.053^{* *} \\
(0.022)\end{array}$ \\
\hline Wage X UR & $\begin{array}{c}1.040^{* * *} \\
(0.189)\end{array}$ & $\begin{array}{c}0.909^{* * *} \\
(0.194)\end{array}$ & $\begin{array}{c}0.931^{* * *} \\
(0.204)\end{array}$ & $\begin{array}{c}1.004^{* * *} \\
(0.212)\end{array}$ \\
\hline Wage X Hour 1 & $\begin{array}{l}-0.003 \\
(0.002)\end{array}$ & $\begin{array}{c}0.003 \\
(0.008)\end{array}$ & $\begin{array}{c}0.001 \\
(0.008)\end{array}$ & $\begin{array}{c}0.011 \\
(0.014)\end{array}$ \\
\hline Wage X Hour 2 & $\begin{array}{c}-0.012^{* * *} \\
(0.003)\end{array}$ & $\begin{array}{c}0.001 \\
(0.009)\end{array}$ & $\begin{array}{l}-0.011 \\
(0.009)\end{array}$ & $\begin{array}{c}0.039^{* * *} \\
(0.013)\end{array}$ \\
\hline Wage X Hour 3 & $\begin{array}{c}-0.014^{* * *} \\
(0.003)\end{array}$ & $\begin{array}{c}0.004 \\
(0.009)\end{array}$ & $\begin{array}{l}-0.006 \\
(0.010)\end{array}$ & $\begin{array}{c}0.037^{* * *} \\
(0.014)\end{array}$ \\
\hline Wage X Hour 4 & $\begin{array}{c}-0.021^{* * *} \\
(0.004)\end{array}$ & $\begin{array}{c}0.004 \\
(0.011)\end{array}$ & $\begin{array}{l}-0.005 \\
(0.011)\end{array}$ & $\begin{array}{l}0.033^{* *} \\
(0.016)\end{array}$ \\
\hline Wage X Hour 5 & $\begin{array}{c}-0.026^{* * *} \\
(0.004)\end{array}$ & $\begin{array}{l}-0.011 \\
(0.011)\end{array}$ & $\begin{array}{l}-0.023^{*} \\
(0.012)\end{array}$ & $\begin{array}{c}0.023 \\
(0.016)\end{array}$ \\
\hline Wage X Hour 6 & $\begin{array}{c}-0.028^{* * *} \\
(0.004)\end{array}$ & $\begin{array}{c}-0.036^{* * *} \\
(0.011)\end{array}$ & $\begin{array}{c}-0.043^{* * *} \\
(0.013)\end{array}$ & $\begin{array}{l}-0.015 \\
(0.016)\end{array}$ \\
\hline Wage X Hour 7 & $\begin{array}{c}-0.027^{* * *} \\
(0.005)\end{array}$ & $\begin{array}{c}-0.060^{* * *} \\
(0.013)\end{array}$ & $\begin{array}{c}-0.072^{* * *} \\
(0.014)\end{array}$ & $\begin{array}{l}-0.028 \\
(0.017)\end{array}$ \\
\hline Wage X Hour 8 & $\begin{array}{c}-0.012^{* *} \\
(0.005)\end{array}$ & $\begin{array}{c}-0.054^{* * *} \\
(0.014)\end{array}$ & $\begin{array}{c}-0.059^{* * *} \\
(0.015)\end{array}$ & $\begin{array}{c}-0.039^{* *} \\
(0.016)\end{array}$ \\
\hline Wage X Hour 9 & $\begin{array}{l}-0.003 \\
(0.004)\end{array}$ & $\begin{array}{c}-0.036^{* * *} \\
(0.014)\end{array}$ & $\begin{array}{c}-0.041^{* * *} \\
(0.015)\end{array}$ & $\begin{array}{l}-0.025 \\
(0.019)\end{array}$ \\
\hline Wage X Hour 10 & $\begin{array}{l}0.007^{*} \\
(0.004)\end{array}$ & $\begin{array}{l}-0.019 \\
(0.012)\end{array}$ & $\begin{array}{l}-0.017 \\
(0.013)\end{array}$ & $\begin{array}{l}-0.026 \\
(0.018)\end{array}$ \\
\hline Wage X Hour 11 & $\begin{array}{l}0.009^{* *} \\
(0.004)\end{array}$ & $\begin{array}{l}-0.016 \\
(0.013)\end{array}$ & $\begin{array}{l}-0.016 \\
(0.014)\end{array}$ & $\begin{array}{l}-0.020 \\
(0.015)\end{array}$ \\
\hline Wage X Hour 12 & $\begin{array}{c}0.008^{* * *} \\
(0.003)\end{array}$ & $\begin{array}{l}-0.013 \\
(0.011)\end{array}$ & $\begin{array}{l}-0.015 \\
(0.012)\end{array}$ & $\begin{array}{l}-0.013 \\
(0.015)\end{array}$ \\
\hline Wage X Hour 13 & $\begin{array}{c}0.008^{* * *} \\
(0.003)\end{array}$ & $\begin{array}{l}-0.000 \\
(0.009)\end{array}$ & $\begin{array}{c}0.001 \\
(0.011)\end{array}$ & $\begin{array}{l}-0.005 \\
(0.013)\end{array}$ \\
\hline Wage X Hour 14 & $\begin{array}{c}0.010^{* * *} \\
(0.003)\end{array}$ & $\begin{array}{l}0.018^{* *} \\
(0.009)\end{array}$ & $\begin{array}{l}0.019^{*} \\
(0.011)\end{array}$ & $\begin{array}{c}0.014 \\
(0.012)\end{array}$ \\
\hline Wage X Hour 15 & $\begin{array}{c}0.016^{* * *} \\
(0.003)\end{array}$ & $\begin{array}{c}0.031^{* * *} \\
(0.009)\end{array}$ & $\begin{array}{c}0.034^{* * *} \\
(0.010)\end{array}$ & $\begin{array}{c}0.020 \\
(0.013)\end{array}$ \\
\hline Wage X Hour 16 & $\begin{array}{c}0.019^{* * *} \\
(0.003)\end{array}$ & $\begin{array}{c}0.028^{* * *} \\
(0.009)\end{array}$ & $\begin{array}{c}0.028^{* * *} \\
(0.009)\end{array}$ & $\begin{array}{l}0.024^{*} \\
(0.015)\end{array}$ \\
\hline Wage X Hour 17 & $\begin{array}{c}0.021^{* * *} \\
(0.002)\end{array}$ & $\begin{array}{c}0.025^{* * *} \\
(0.008)\end{array}$ & $\begin{array}{c}0.026^{* * *} \\
(0.008)\end{array}$ & $\begin{array}{c}0.020 \\
(0.012)\end{array}$ \\
\hline Wage X Hour 18 & $\begin{array}{c}0.022^{* * *} \\
(0.003)\end{array}$ & $\begin{array}{l}0.017^{* *} \\
(0.007)\end{array}$ & $\begin{array}{c}0.010 \\
(0.008)\end{array}$ & $\begin{array}{c}0.038^{* * *} \\
(0.012)\end{array}$ \\
\hline Wage X Hour 19 & $\begin{array}{c}0.017^{* * *} \\
(0.002)\end{array}$ & $\begin{array}{c}0.008 \\
(0.007)\end{array}$ & $\begin{array}{c}0.002 \\
(0.008)\end{array}$ & $\begin{array}{l}0.030^{* *} \\
(0.013)\end{array}$ \\
\hline Wage X Hour 20 & $\begin{array}{c}0.011^{* * *} \\
(0.002)\end{array}$ & $\begin{array}{l}-0.004 \\
(0.008)\end{array}$ & $\begin{array}{l}-0.010 \\
(0.009)\end{array}$ & $\begin{array}{c}0.016 \\
(0.014)\end{array}$ \\
\hline Wage X Hour 21 & $\begin{array}{c}0.011^{* * *} \\
(0.002)\end{array}$ & $\begin{array}{c}-0.013^{*} \\
(0.007)\end{array}$ & $\begin{array}{c}-0.023^{* * *} \\
(0.008)\end{array}$ & $\begin{array}{c}0.019 \\
(0.012)\end{array}$ \\
\hline
\end{tabular}




\begin{tabular}{|c|c|c|c|c|}
\hline Wage X Hour 22 & $\begin{array}{c}0.010^{* * *} \\
(0.002)\end{array}$ & $\begin{array}{c}0.001 \\
(0.007)\end{array}$ & $\begin{array}{c}-0.009 \\
(0.009)\end{array}$ & $\begin{array}{c}0.031^{* * *} \\
(0.011)\end{array}$ \\
\hline Wage X Hour 23 & $\begin{array}{c}0.007^{* * *} \\
(0.002)\end{array}$ & $\begin{array}{c}-0.014^{* *} \\
(0.007)\end{array}$ & $\begin{array}{c}-0.018^{* *} \\
(0.007)\end{array}$ & $\begin{array}{l}-0.003 \\
(0.012)\end{array}$ \\
\hline Wage X Weekend & $\begin{array}{c}-0.011^{* * *} \\
(0.001)\end{array}$ & $\begin{array}{c}-0.025^{* * *} \\
(0.003)\end{array}$ & & \\
\hline Wage X UR X Hour 1 & & $\begin{array}{l}-0.093 \\
(0.094)\end{array}$ & $\begin{array}{l}-0.086 \\
(0.100)\end{array}$ & $\begin{array}{c}-0.113 \\
(0.180)\end{array}$ \\
\hline Wage X UR X Hour 2 & & $\begin{array}{l}-0.179 \\
(0.118)\end{array}$ & $\begin{array}{l}-0.059 \\
(0.131)\end{array}$ & $\begin{array}{c}-0.562^{* * *} \\
(0.163)\end{array}$ \\
\hline Wage X UR X Hour 3 & & $\begin{array}{c}-0.259^{* *} \\
(0.120)\end{array}$ & $\begin{array}{l}-0.143 \\
(0.133)\end{array}$ & $\begin{array}{c}-0.609^{* * *} \\
(0.169)\end{array}$ \\
\hline Wage X UR X Hour 4 & & $\begin{array}{c}-0.360^{* *} \\
(0.150)\end{array}$ & $\begin{array}{c}-0.261^{*} \\
(0.158)\end{array}$ & $\begin{array}{c}-0.676^{* * *} \\
(0.208)\end{array}$ \\
\hline Wage X UR X Hour 5 & & $\begin{array}{l}-0.211 \\
(0.154)\end{array}$ & $\begin{array}{c}-0.098 \\
(0.168)\end{array}$ & $\begin{array}{c}-0.549^{* * *} \\
(0.202)\end{array}$ \\
\hline Wage X UR X Hour 6 & & $\begin{array}{c}0.103 \\
(0.155)\end{array}$ & $\begin{array}{c}0.156 \\
(0.182)\end{array}$ & $\begin{array}{c}-0.072 \\
(0.205)\end{array}$ \\
\hline Wage X UR X Hour 7 & & $\begin{array}{l}0.436^{* *} \\
(0.177)\end{array}$ & $\begin{array}{c}0.580^{* * * *} \\
(0.190)\end{array}$ & $\begin{array}{c}0.029 \\
(0.227)\end{array}$ \\
\hline Wage X UR X Hour 8 & & $\begin{array}{c}0.534^{* * *} \\
(0.172)\end{array}$ & $\begin{array}{c}0.624^{* * *} \\
(0.187)\end{array}$ & $\begin{array}{c}0.290 \\
(0.191)\end{array}$ \\
\hline Wage X UR X Hour 9 & & $\begin{array}{c}0.420^{* * *} \\
(0.153)\end{array}$ & $\begin{array}{c}0.491^{* * *} \\
(0.163)\end{array}$ & $\begin{array}{c}0.227 \\
(0.223)\end{array}$ \\
\hline Wage X UR X Hour 10 & & $\begin{array}{l}0.318^{* *} \\
(0.138)\end{array}$ & $\begin{array}{c}0.297^{* *} \\
(0.143)\end{array}$ & $\begin{array}{c}0.405^{*} \\
(0.214)\end{array}$ \\
\hline Wage X UR X Hour 11 & & $\begin{array}{l}0.315^{* *} \\
(0.139)\end{array}$ & $\begin{array}{c}0.306^{* *} \\
(0.154)\end{array}$ & $\begin{array}{c}0.352^{*} \\
(0.180)\end{array}$ \\
\hline Wage X UR X Hour 12 & & $\begin{array}{l}0.269^{* *} \\
(0.127)\end{array}$ & $\begin{array}{l}0.296^{* *} \\
(0.137)\end{array}$ & $\begin{array}{c}0.235 \\
(0.178)\end{array}$ \\
\hline Wage X UR X Hour 13 & & $\begin{array}{c}0.104 \\
(0.112)\end{array}$ & $\begin{array}{c}0.095 \\
(0.131)\end{array}$ & $\begin{array}{c}0.151 \\
(0.159)\end{array}$ \\
\hline Wage X UR X Hour 14 & & $\begin{array}{l}-0.100 \\
(0.107)\end{array}$ & $\begin{array}{l}-0.083 \\
(0.122)\end{array}$ & $\begin{array}{l}-0.115 \\
(0.146)\end{array}$ \\
\hline Wage X UR X Hour 15 & & $\begin{array}{c}-0.196^{*} \\
(0.109)\end{array}$ & $\begin{array}{c}-0.213^{*} \\
(0.125)\end{array}$ & $\begin{array}{c}-0.119 \\
(0.145)\end{array}$ \\
\hline Wage X UR X Hour 16 & & $\begin{array}{l}-0.104 \\
(0.102)\end{array}$ & $\begin{array}{c}-0.083 \\
(0.103)\end{array}$ & $\begin{array}{c}-0.143 \\
(0.177)\end{array}$ \\
\hline Wage X UR X Hour 17 & & $\begin{array}{l}-0.041 \\
(0.096)\end{array}$ & $\begin{array}{c}-0.038 \\
(0.104)\end{array}$ & $\begin{array}{c}-0.021 \\
(0.153)\end{array}$ \\
\hline Wage X UR X Hour 18 & & $\begin{array}{c}0.062 \\
(0.084)\end{array}$ & $\begin{array}{c}0.144 \\
(0.098)\end{array}$ & $\begin{array}{c}-0.176 \\
(0.156)\end{array}$ \\
\hline Wage X UR X Hour 19 & & $\begin{array}{c}0.118 \\
(0.084)\end{array}$ & $\begin{array}{l}0.200^{* *} \\
(0.098)\end{array}$ & $\begin{array}{l}-0.149 \\
(0.162)\end{array}$ \\
\hline Wage X UR X Hour 20 & & $\begin{array}{l}0.185^{* *} \\
(0.088)\end{array}$ & $\begin{array}{l}0.255^{* *} \\
(0.102)\end{array}$ & $\begin{array}{c}-0.016 \\
(0.169)\end{array}$ \\
\hline Wage X UR X Hour 21 & & $\begin{array}{c}0.312^{* * *} \\
(0.084)\end{array}$ & $\begin{array}{c}0.433^{* * *} \\
(0.093)\end{array}$ & $\begin{array}{c}-0.048 \\
(0.152)\end{array}$ \\
\hline Wage X UR X Hour 22 & & $\begin{array}{c}0.116 \\
(0.089)\end{array}$ & $\begin{array}{l}0.228^{* *} \\
(0.111)\end{array}$ & $\begin{array}{c}-0.231 \\
(0.149)\end{array}$ \\
\hline Wage X UR X Hour 23 & & $0.274^{* * *}$ & $0.316^{* * *}$ & 0.154 \\
\hline
\end{tabular}




\begin{tabular}{lcccc}
\hline Wage X UR X Weekend & & $(0.090)$ & $(0.094)$ & $(0.152)$ \\
& & $0.174^{* * *}$ & & \\
Controls & Yes & Yes & Yes & Yes \\
\hline$R^{2}$ Overall & 0.16 & 0.16 & 0.17 & 0.15 \\
$R^{2}$ Within & 0.18 & 0.18 & 0.19 & 0.18 \\
Observations & 486814 & 486814 & 358794 & 128020 \\
\hline \hline
\end{tabular}

NoTE: The table shows regressions of unemployment on the activity in the online labor market by the hour of the day. The dependent variable is the odds-ratio for working hours. Col. 1 shows the distribution of activity across the day, and in Columns 2-4 we introduce interactions of wage and the daily hours with unemployment. We separately show our results for all days of the week (Col. 1-2), and then separately for regular weekdays (Col. 3) and weekends (Col. 4). Standard errors in parentheses are clustered by commuting zone and robust to heteroscedasticity and autocorrelation. ${ }^{*} \mathrm{p}<0.1,{ }^{* *} \mathrm{p}<0.05,{ }^{* * *} \mathrm{p}<0.01$. 